\title{
Evaluation of recently-proposed secondary organic aerosol models for a case study in Mexico City
}

\author{
K. Dzepina ${ }^{1,2,3}$, R. M. Volkamer ${ }^{2}$, S. Madronich ${ }^{3}$, P. Tulet ${ }^{1,3,4}$, I. M. Ulbrich ${ }^{1,2}$, Q. Zhang ${ }^{5}$, C. D. Cappa ${ }^{6}$, \\ P. J. Ziemann ${ }^{7}$, and J. L. Jimenez ${ }^{1,2}$ \\ ${ }^{1}$ Cooperative Institute for Research in the Environmental Sciences (CIRES), Univ. of Colorado at Boulder, Boulder, CO, USA \\ ${ }^{2}$ Department of Chemistry and Biochemistry, University of Colorado at Boulder, Boulder, CO, USA \\ ${ }^{3}$ National Center for Atmospheric Research - Atmospheric Chemistry Division, Boulder, CO, USA \\ ${ }^{4}$ Meteo France/CNRM-GAME, Toulouse, France \\ ${ }^{5}$ Atmospheric Sciences Research Center, University at Albany, SUNY, Albany, NY, USA \\ ${ }^{6}$ Department of Civil and Environmental Engineering, University of California at Davis, Davis, CA, USA \\ ${ }^{7}$ Air Pollution Research Center, University of California, Riverside, CA, USA
}

Received: 8 December 2008 - Published in Atmos. Chem. Phys. Discuss.: 17 February 2009

Revised: 14 July 2009 - Accepted: 21 July 2009 - Published: 10 August 2009

\begin{abstract}
Recent field studies have found large discrepancies in the measured vs. modeled SOA mass loadings in both urban and regional polluted atmospheres. The reasons for these large differences are unclear. Here we revisit a case study of SOA formation in Mexico City described by Volkamer et al. (2006), during a photochemically active period when the impact of regional biomass burning is minor or negligible, and show that the observed increase in $\mathrm{OA} / \Delta \mathrm{CO}$ is consistent with results from several groups during MILAGRO 2006. Then we use the case study to evaluate three new SOA models: 1) the update of aromatic SOA yields from recent chamber experiments (Ng et al., 2007); 2) the formation of SOA from glyoxal (Volkamer et al., 2007a); and 3) the formation of SOA from primary semivolatile and intermediate volatility species (P-S/IVOC) (Robinson et al., 2007). We also evaluate the effect of reduced partitioning of SOA into POA (Song et al., 2007). Traditional SOA precursors (mainly aromatics) by themselves still fail to produce enough SOA to match the observations by a factor of $\sim 7$. The new low- $\mathrm{NO}_{\mathrm{x}}$ aromatic pathways with very high SOA yields make a very small contribution in this high- $\mathrm{NO}_{\mathrm{x}}$ urban environment as the $\mathrm{RO}_{2}+\mathrm{NO}$ reaction dominates the fate of the $\mathrm{RO}_{2}$ radicals. Glyoxal contributes several $\mu \mathrm{g} \mathrm{m}^{-3}$ to SOA formation, with similar timing as the measurements. P-S/IVOC are estimated from equilibrium with emitted POA, and introduce a large
\end{abstract}

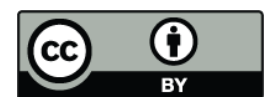

Correspondence to: J. L. Jimenez (jose.jimenez@colorado.edu) amount of gas-phase oxidizable carbon that was not in models before. With the formulation in Robinson et al. (2007) these species have a high SOA yield, and this mechanism can close the gap in SOA mass between measurements and models in our case study. However the volatility of SOA produced in the model is too high and the $\mathrm{O} / \mathrm{C}$ ratio is somewhat lower than observations. Glyoxal SOA helps to bring the O/C ratio of predicted and observed SOA into better agreement. The sensitivities of the model to some key uncertain parameters are evaluated.

\section{Introduction}

Recent research has clearly demonstrated the importance of atmospheric aerosols for air quality and radiative forcing of climate. Organic species in particles, typically referred to as "organic aerosols" (OA) comprise $20-90 \%$ of total fine particulate mass in the atmosphere (Kanakidou et al., 2005; Murphy et al., 2006; Zhang et al., 2007) and can significantly contribute to the effects of aerosols. OA is customarily divided into primary and secondary OA (POA and SOA, respectively). POA is emitted directly into the atmosphere in particle form (e.g. from combustion sources), while SOA is produced by reactions of gaseous organic precursors. Abbreviations used in this paper are summarized in Supp. Info Sect. 1 (http://www.atmos-chem-phys.net/9/5681/2009/ acp-9-5681-2009-supplement.pdf).

Published by Copernicus Publications on behalf of the European Geosciences Union. 
Recent field studies have found large discrepancies between the SOA mass concentrations estimated from measurements and those calculated from traditional SOA models in both urban and regional polluted atmospheres (Heald et al., 2005; de Gouw et al., 2005; Johnson et al., 2006; Volkamer et al., 2006; Kleinman et al., 2008; Matsui et al., 2009). Volkamer et al. (2006) presented a case study from Mexico City in which SOA formation was observed experimentally over short time scales not accessible in the previous studies. The measured SOA was about 8 times larger than a conservative (high end) estimate from a SOA model based on empirical parameterization of chamber experiments. Their results were recently corroborated by Kleinman et al. (2008) who reported a similar discrepancy of about an order of magnitude higher measured SOA than that expected from aromatic oxidation for Mexico City using aircraft data from the MILAGRO 2006 campaign, and Hodzic et al. (2009) and Tsimpidi et al. (2009) who report model-measurement discrepancies of the same order when using traditional SOA models inside two different regional models over Mexico City. Chamber studies of SOA formation from diluted diesel exhaust and wood smoke also indicate very large discrepancies between measured and model SOA, very similar to what is observed in field studies (Robinson et al., 2007; Grieshop et al., 2009a).

The reasons for the large measured/model differences remain unclear, and several hypotheses have been put forward. $\mathrm{Ng}$ et al. (2007) re-studied in chamber experiments the SOA yields from aromatics with high SOA yield (benzene, toluene and m-xylene) and found that their SOA yields are higher than determined in previous experiments. Robinson et al. (2007) included semivolatile primary emissions that were previously neglected as SOA precursors. With this modification Robinson et al. (2007) found that OA was more regionally distributed and more dominated by SOA, and in better agreement with observations. Volkamer et al. (2007a) recognized glyoxal as another previously neglected SOA precursor, as traditionally glyoxal was considered too volatile to partition to the particle-phase. The possibility of accretion reactions that produce species of much lower volatility was recognized by e.g. Kalberer et al. (2004), and Barsanti and Pankow (2005), and likely also explains the formation of SOA from glyoxal (Volkamer et al., 2009). Song et al. (2007) showed that POA mass may not be fully available for partitioning of SOA. SOA formation in clouds can be important in some locations (e.g. Ervens et al., 2008) but it is estimated to make at most a minor contribution to this case study (Volkamer et al., 2006).

In this paper, we revisit the SOA case study from Mexico City that was analyzed by Volkamer et al. (2006) and compare SOA measurements against model SOA predicted by inclusion of several recently proposed SOA mechanisms. This case is shown to be representative by comparison to MILAGRO data and by analyzing six other days of MCMA-2003. The properties of the SOA formed in the various models are characterized by their evolution upon heating, dilution, photochemical aging, and by their $\mathrm{O} / \mathrm{C}$ ratios. Finally, the sensitivity of the model results to several key parameters is evaluated.

\section{Experimental}

\subsection{Measurements}

The Mexico City Metropolitan Area 2003 field campaign (MCMA-2003) took place from 29 March to 4 May 2003 at the CENICA Supersite (Salcedo et al., 2006; Molina et al., 2007, and references therein). Here, we will briefly describe the measurements used in this paper, and refer the reader to the published papers for additional detail. Volatile organic compounds (VOC) were measured by two methods, openpath Differential Optical Absorption Spectroscopy (DOAS) (Volkamer et al., 1998) and GC-FID analysis of canister samples (Lamb et al., 2004). Detailed descriptions of the MCMA-2003 VOC measurements and total $\mathrm{OH}$ reactivity are given elsewhere (Velasco et al., 2007; Volkamer et al., 2007b; Sheehy et al., 2008). Glyoxal and ozone were measured by DOAS (Volkamer et al., 2005). $\mathrm{OH}^{\circ}$ and $\mathrm{HO}_{2}$ radical concentrations were measured by Laser Induced Fluorescence (LIF) (Shirley et al., 2006). Recently it was found that the concentrations of $\mathrm{OH}$ radicals measured during MCMA2003 are larger than reported by Shirley et al. (2006) due to a previously unrecognized calibration error; thus, in this paper the $\mathrm{OH}$ measurements are increased by $30 \%$ compared to those used in Volkamer et al. (2006) (W. Brune, Penn State, personal communication, 2007). Gas-phase species and meteorological parameters were measured by CENICA scientists (de Foy et al., 2005). The height of planetary boundary layer (PBL) was estimated from two measurement techniques (radiosondes and chemical tracer approach) and meteorological modeling (MM5 model) (Volkamer et al., 2006; de Foy et al., 2005). Black carbon was measured using a seven-channel aethalometer (RTAA-1000, Magee Scientific, Berkeley, CA) (Marley et al., 2007).

Non-refractory submicron particle species $\left(\mathrm{NR}-\mathrm{PM}_{1}\right)$ were measured using a quadrupole-based Aerodyne Aerosol Mass Spectrometer (Q-AMS) (Jayne et al., 2000; Jimenez et al., 2003; Canagaratna et al., 2007), as reported by Salcedo et al. (2006, 2007). The Q-AMS MCMA-2003 data have been extensively compared to collocated instruments (Salcedo et al., 2005, 2006; Dzepina et al., 2007; Johnson et al., 2008). The total OA concentration is deconvolved by factor analysis of the AMS organic mass spectrum (Zhang et al., 2005a,b, 2007; Takegawa et al., 2006; Kondo et al., 2007; Lanz et al., 2007; Nemitz et al., 2008; Aiken et al., 2008; Docherty et al., 2008; Ulbrich et al., 2009) using Positive Matrix Factorization (PMF) (Paatero, 1997; Paatero and Tapper, 1994). The four components resolved in this study are consistent with those determined 


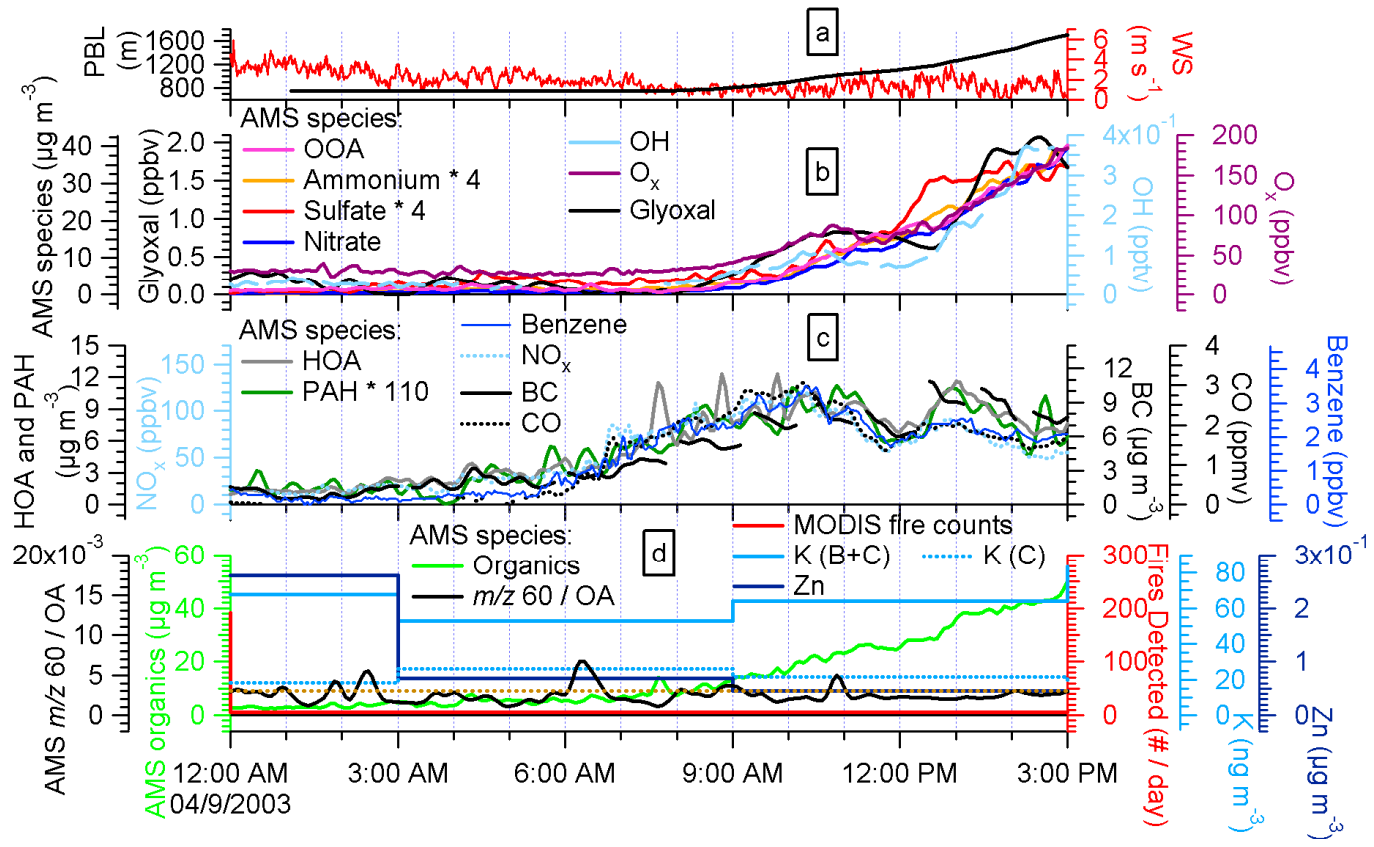

Fig. 1. Evolution of meteorological parameters, gas- and particle-phase species during 9 April 2003. Panel (a) shows the basic meteorology, and panels (b), (c) and (d) give the evolution of markers and species from secondary, primary, and biomass burning and industrial sources, respectively. K data are shown for DRUM stage $\mathrm{C}(0.07-0.34 \mu \mathrm{m})$ and stages $\mathrm{B}+\mathrm{C}(0.07-1.15 \mu \mathrm{m}) . \mathrm{m} / \mathrm{z}$. 60/OA is compared with the level typically observed in the absence of biomass burning influence $(0.3 \%$, dashed yellow line).

in multiple previous factor analyses of AMS spectra (cited above) and also with those of the AMS data from the MILAGRO campaign analyzed using PMF (Aiken et al., 2008): hydrocarbon-like OA (HOA) which is interpreted as a surrogate of reduced primary emissions, two types of oxygenated OA (OOA-1 and OOA-2) which are interpreted as SOA surrogates, and biomass burning OA (BBOA). $\mathrm{BBOA}$ is negligible during our case study. In this paper, we use "OOA" to refer to the total OOA (OOA-1+OOA2). Additional justification of these assignments is given in Supp. Info. Sect. 2 (http://www.atmos-chem-phys.net/9/ 5681/2009/acp-9-5681-2009-supplement.pdf). We note that several recent studies have shown that the estimate of SOA based on total OOA from the AMS is consistent with estimates from other methods such as the EC-tracer method (Zhang et al., 2005), WSOC (Kondo et al., 2007), the COtracer method (Takegawa et al., 2006), the chemical mass balance of organic molecular markers (Aiken et al., 2009), and with all four of those methods at one location (Docherty et al., 2008). The previous Volkamer et al. (2006) study used results for HOA and total OOA from the earlier custom principal component analysis method (CPCA; Zhang et al., 2005a). The PMF results for 9 April 2003 are similar to those from the CPCA, as shown in Fig. SI-1: on average, total OOA is $11 \%$ larger and HOA is $21 \%$ smaller when using PMF instead of CPCA, and the time series are very similar for both methods. Figure SI-1 also shows that OOA2 (the less oxidized component) rises faster in the morning than OOA-1 (the more aged and oxidized component). In principle, fresher SOA should be less oxygenated than more aged SOA, and thus the chemical structure of freshly formed SOA could resemble HOA more than OOA. However, chamber experiments starting from diesel and wood burning emissions have shown that the AMS spectrum of the SOA formed from these emissions resembles OOA (in particular the subtype of OOA known as OOA-2) very quickly (Sage et al., 2008; Grieshop et al., 2009b). This surprising observation is being investigated in detail in the laboratory starting from IVOC precursors (Presto et al., 2009). Finally, and as shown in Fig. 1, there is a good correlation between the time series of HOA and other primary tracers. If the HOA determined with PMF had a major contribution from less-oxidized SOA, it should show an increase above the relative levels of the other primary tracers in the afternoon, but it does not within the variability of the measurements. Thus, we conclude that HOA and total OOA are indeed best interpreted as surrogates for total POA and total SOA respectively.

\subsection{Meteorology and description of the case study}

The variations in ambient concentrations of SOA and its precursors measured at a fixed site are the result of the complex interplay of emissions, horizontal and vertical advection and mixing due to the meteorology, chemical transformations, and removal processes such as dry and wet deposition. The case study of 9 April 2003 received detailed focus 


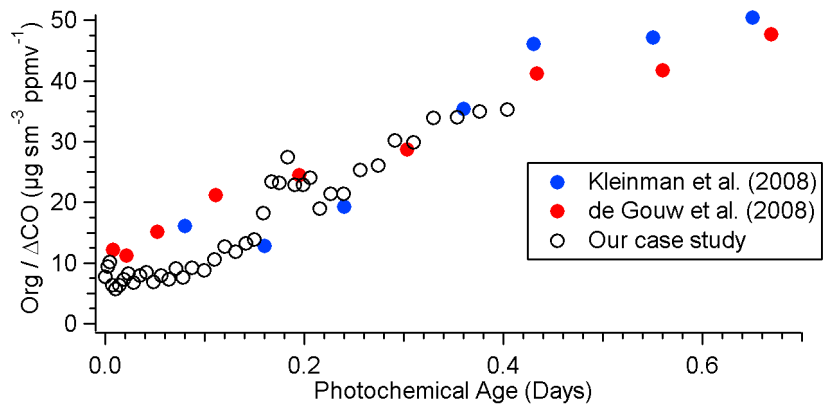

Fig. 2. Evolution of $\mathrm{OA} / \triangle \mathrm{CO}$ vs. photochemical age for our case study during MCMA-2003, and for data from Kleinman et al. (2008) and de Gouw et al. (2009) during MILAGRO. We define $\triangle \mathrm{CO}$ to account for the typical $\mathrm{CO}$ background, and $\Delta \mathrm{CO}=\mathrm{CO}_{\text {Measured }}-100 \mathrm{ppb}$. Concentrations are shown in STP conditions of $273.15 \mathrm{~K}$ and $1 \mathrm{~atm}$.

in the present study, as well as in the study of Volkamer et al. (2006), because of the relatively simple meteorology and low background concentrations of pollutants. Note that Volkamer et al. (2006) reported that analyses performed for other days gave consistent results.

This day started with very low pollutant concentrations due to the arrival of clean air with a "Norte" or "Cold Surge" event (de Foy et al., 2005). Figure 1a shows that the horizontal wind speed is low throughout the day, and the maximum planetary boundary layer (PBL) height, which typically reaches $\sim 3000-4000 \mathrm{~m}$, increased to only $\sim 1800 \mathrm{~m}$. Thus, fresh emissions accumulated in the city, especially during the traffic rush hour in the morning.

AMS HOA is well correlated with primary emission tracers such as $\mathrm{CO}$, black carbon $(\mathrm{BC}), \mathrm{NO}_{\mathrm{x}}$, benzene and $\mathrm{PAH}$ (Fig. 1c). OOA and other secondary species did not increase at all in the early morning when primary species are increasing, and increased as soon as the photochemistry was initiated. Figure $1 \mathrm{~b}$ shows that AMS OOA is well correlated with photochemical tracers such as $\mathrm{OH}^{-}, \mathrm{O}_{\mathrm{x}}$ $\left(=\mathrm{O}_{3}+\mathrm{NO}_{2}\right)$, gas-phase glyoxal and particulate nitrate. To characterize the correlation between AMS HOA and OOA and other tracers, we calculated $r$ values between AMS HOA and OOA and primary and secondary tracers, respectively, for 9 April 2003 between 6 a.m. and 6 p.m. There is a strong correlation between AMS HOA and CO, black carbon, $\mathrm{NO}_{\mathrm{x}}$, benzene, toluene and AMS PAH, resulting in $r$ values of $0.68,0.75,0.62,0.78,0.66$ and 0.76 , respectively. AMS OOA is strongly correlated with $\mathrm{OH}, \mathrm{O}_{\mathrm{x}}$, glyoxal and AMS nitrate, with $r$ values of 0.92 , $0.95,0.94$, and 0.99 , respectively, which indicates very similar behavior of all secondary species. Detailed discussion on the agreement between HOA and OOA and primary and secondary markers, respectively, is given in Supp. Info. Sect. SI-2 (http://www.atmos-chem-phys.net/9/5681/ 2009/acp-9-5681-2009-supplement.pdf). After $\sim 4$ p.m. the concentrations of most species start to decrease as the wind speed increases, most likely due to horizontal advection leading to the arrival of cleaner air that started the day outside of the edge of the city and had undergone less accumulation of pollutants. For this reason the modeling is only carried out until 2 p.m. Note that the wind speed is low during the morning hours and that the comparisons between model and measurements do not need to consider the entire period. For example, the increase in SOA between 9 and 10 a.m. can be compared between measurements and models, similarly from 10 to $11 \mathrm{a} . \mathrm{m}$. and so on. During one hour in the morning the air in the city traveled about $3 \mathrm{~km}$, which is small compared to the characteristic dimension of the city of 40$50 \mathrm{~km}$, thus the effect of spatial inhomogeneity is expected to be small over the short time scale of this model study. In this paper, all particle concentrations (with units of $\mu \mathrm{g} \mathrm{m}^{-3}$ ) are reported under ambient conditions unless otherwise specified. To obtain concentrations under standard conditions ( $\mu \mathrm{g} \mathrm{sm}^{-3}$ at STP, $273 \mathrm{~K}$ and $\left.1 \mathrm{~atm}\right)$ the particle concentrations reported here should be multiplied by $\sim 1.42$.

To rule out that the results for 9 April 2003 might be due to the atypical conditions we corroborate previous analysis of other days (Volkamer et al., 2006) and show results from six other days of MCMA-2003 in Sects. 4.1 and 4.4, all of which give similar results to those from our case study. To further evaluate the representativeness of our case study for typical SOA formation in Mexico City we show in Fig. 2 the evolution of $\mathrm{OA} / \triangle \mathrm{CO}$ vs. photochemical age for our case study and for data from Kleinman et al. (2008) and de Gouw et al. (2009) during MILAGRO 2006. We calculated the photochemical age for our case study and for de Gouw et al. (2009) by defining the start of photochemistry (age $=0$ days) to be the time when $\mathrm{OH}$ starts rising in the morning, and age $=1$ at the end of the photochemically-active period after sunset. We define the photochemical age as the integral $\mathrm{OH}-$ exposure until a given point in time, divided by the average $\mathrm{OH}$ exposure during MCMA-2003 based on the measurements of Shirley et al. (2006), updated with the revision of their calibrations described above. A detailed description of the photochemical age calculation for Kleinman et al. (2008) is given in their manuscript. Briefly, Kleinman et al. (2008) define the photochemical age as $-\log _{10}\left(\mathrm{NO}_{\mathrm{x}} / \mathrm{NO}_{\mathrm{y}}\right)$, with a value of 0 for fresh emissions $\left(\right.$ as $\mathrm{NO}_{\mathrm{y}}=\mathrm{NO}_{\mathrm{x}}$ ) and a value of 1 when $90 \%$ of $\mathrm{NO}_{\mathrm{x}}$ is converted into oxidation products. The $\mathrm{OA} / \Delta \mathrm{CO}$ ratio for our case study ranges from $\sim 8-$ $35 \mu \mathrm{g} \mathrm{sm}^{-3} \mathrm{ppmv}^{-1}$. The initial values are typical of urban POA with a small SOA background (e.g. Zhang et al., 2005b; Aiken et al., 2009). The different studies produce similar increases in $\mathrm{OA} / \triangle \mathrm{CO}$ vs. photochemical age, which strongly indicates that our case study represents the typical SOA formation under photochemical evolution of urban emissions in Mexico City, which reaches higher absolute concentrations in our case due to the particular meteorology favoring reduced dilution as stated above. The modeling exercise in this paper could in fact be performed by simulating the 
evolution of urban emissions vs. photochemical age shown in Fig. 2, instead of simulating 9 April 2003. However we prefer to model this particular case study as it is more strongly constrained by highly time-resolved measurements of VOC, $\mathrm{HO}_{\mathrm{x}}, \mathrm{O}_{3}$, aerosols, etc. The fact that the model is so strongly constrained by measurements eliminates many uncertainties associated with, e.g., advection, in an Eulerian 3-D model.

As an additional piece of evidence that the evolution of OOA during our case study is dominated by gas-toparticle conversion, the evolution of the AMS size distributions of NR-PM $\mathrm{PM}_{1}$ species during this day is shown in Fig. SI-2 (http://www.atmos-chem-phys.net/9/5681/2009/ acp-9-5681-2009-supplement.pdf). While the estimated HOA size distribution is dominated by smaller primary particles, as observed in other studies (e.g., Zhang et al., 2005b), the estimated OOA size distribution evolves very similarly to that of ammonium nitrate, a species that is known to be exclusively formed by gas-to-particle conversion. Finally, the effect of uncertainties in mixing height evolution on the SOA model results is investigated in Sect. 5.3.

\section{SOA modeling methods}

\subsection{Gas-particle partitioning}

We treat gas-particle partitioning of semivolatile organics as occurring by absorption into an organic aerosol phase (Pankow, 1994a, b). Partitioning calculations in this manuscript assume that the aerosol and semivolatile species in the gas phase are in thermodynamic equilibrium, which is reasonable based on the time scales of gas-particle equilibrium for submicron particles (Seinfeld and Pandis, 1998). In this paper we use the reformulation of the Pankow theory by Donahue et al. (2006), in which the particle-phase fraction of a species is calculated as:

$X_{p, i}=\frac{1}{1+\frac{c_{i}^{*}}{c_{O A}}}$

where $c_{i}^{*}\left(\mu \mathrm{g} \mathrm{m}^{-3}\right)$ is the effective saturation concentration of condensable compound $i$, and $c_{O A}\left(\mu \mathrm{g} \mathrm{m}^{-3}\right)$ is the mass concentration of the absorbing organic phase. Please note that Pankow (1994a) defined the absorption partitioning coefficient $K_{o m, i}\left(\mathrm{~m}^{3} \mu \mathrm{g}^{-1}\right)$ as:

$K_{o m, i}=\frac{1}{\zeta_{i} c_{i}^{*}}$

where $\zeta_{i}$ is the activity coefficient of condensable species $i$ in the absorbing organic phase. Thus, Eq. (1) is strictly true only when $\zeta_{i}=1$.

This formulation neglects the effect of changes in the average molecular weight of the absorbing phase, which could be important especially if a significant amount of water is present in the SOA phase (Chang and Pankow, 2008). The activity coefficients, if known, can be lumped into $c_{i} *$ with no additional error. The information to implement the more complete theory is not available for the mechanisms discussed here, so these effects are neglected in our study. Given the large uncertainties in the SOA models presented here, these partitioning effects are not expected to dominate the prediction uncertainties.

The temperature dependence of saturation concentrations is calculated by the Clausius-Clapeyron equation

$c_{i}^{*}=c_{i, o}^{*} \frac{T_{0}}{T} \exp \left[\frac{\Delta H_{\mathrm{vap}}}{R}\left(\frac{1}{T_{0}}-\frac{1}{T}\right)\right]$

where $c_{i} *\left(\mu \mathrm{g} \mathrm{m}^{-3}\right)$ and $c_{i, 0} *\left(\mu \mathrm{g} \mathrm{m}^{-3}\right)$ are the effective saturation concentrations of condensable compound $i$ at temperature $T(\mathrm{~K})$ and at reference temperature $T_{0}(\mathrm{~K})$, respectively, $\Delta H_{\text {vap }}\left(\mathrm{kJ} \mathrm{mol}^{-1}\right)$ is the enthalpy of vaporization and $R$ is the ideal gas constant.

\subsection{Description of the photochemical box-model}

We approximate the Mexico City atmosphere as a box with a movable top in which the total mass of primary emitted and secondary formed species accumulates and is diluted by mixing of the air from aloft. The concentration of OA in the air aloft is expected to be very low after the arrival of clean air from the Cold Surge event and during this period in which biomass burning is suppressed, consistent with regional observations (DeCarlo et al., 2008). Note that even during a period with intense biomass burning during the MILAGRO campaign the background OA above the city was only $\sim 2.5 \mu \mathrm{g} \mathrm{m}^{-3}$ (Herndon et al., 2008), thus the even smaller background OA expected for this period does not significantly affect our results. As described below, the air mixed in from aloft and diluting the species in the box-model is assumed to have a constant background SOA of $1.4 \mu \mathrm{g} \mathrm{m}^{-3}$ as an upper limit for this effect.

For each model species $i$ the change of its total mass $M_{i}$ inside the box per unit surface area of the city and per time $t$ can be written as:

$\frac{d M_{i}}{d t}=E_{i}+P_{i}-R_{i}+H A_{\text {in }}-H A_{\text {out }}+V M_{\text {in }}$

where $E_{i}$ is the emission of species $i, P_{i}$ and $R_{i}$ are chemical production and destruction, respectively, of species $i, H A_{\text {in }}$ and $H A_{\text {out }}$ is the horizontal advection that brings pollution into or out of the box, respectively, and $V M_{\text {in }}$ is the input of background SOA from vertical mixing of air aloft. For our case study, we assume that differential horizontal advection is small due to the low wind speeds and relatively homogeneous conditions inside this large city (see Sect. 2.2) and thus we set $H A_{\text {in }}-H A_{\text {out }}$ to zero.

The concentration of species $i$ will thus change due to emissions, chemical production and destruction, and dilution by the rising planetary boundary layer:

$\frac{d\left(V_{b} * c_{i}\right)}{d t}=E_{i}+P_{i}-R_{i}+V M_{\text {in }}$ 
where $V_{b}$ is the volume of the box.

Dry deposition (DD) of both gases and particles are neglected in our model. This is a conservative assumption to maximize the amount of SOA produced by the model: if DD was included, it would reduce the modeled SOA and thus increase any discrepancy with the measurements. The DD of submicron particles is much slower than for gases. For example, Nemitz et al. (2008) recently reported measurements of the dry deposition velocity of submicron aerosols for an urban area at low wind speeds to be of the order of $1 \mathrm{~mm} \mathrm{~s}^{-1}$, which for a well-mixed PBL depth of $1000 \mathrm{~m}$ will remove only $2 \%$ of the aerosol mass in $6 \mathrm{~h}$. The DD of oxidized gasphase species can be significantly faster. The range of deposition velocities estimated by current regional model parameterizations (Wesely et al., 1989) for $\mathrm{HNO}_{3}$ in Mexico City during MILAGRO is $7-60 \mathrm{~mm} \mathrm{~s}^{-1}$ (J. Fast, personal communication, 2008). This is likely an upper limit for the deposition velocity of oxygenated $\mathrm{SVOC}$, since $\mathrm{HNO}_{3}$ is known to deposit very quickly compared to most other gas-phase molecules and most oxygenated SVOC should be less polar than $\mathrm{HNO}_{3}$. If that range of deposition velocities was applicable to oxygenated SVOC over a well-mixed PBL of $1000 \mathrm{~m}, 14-73 \%$ of the SVOC initially present would be removed in $6 \mathrm{~h}$, which would reduce the predicted SOA by all models.

\subsection{Updated traditional SOA model (UT model)}

As the first component of our SOA model we update the "traditional SOA model" ("T model") of Koo et al. (2003), with revised SOA yields for aromatic species from $\mathrm{Ng}$ et al. (2007). The traditional approach predicts the SOA formed from measured VOC precursors and oxidants (such as $\mathrm{OH}^{\circ}$ and $\mathrm{O}_{3}$ ) using empirical 2-product parameterizations of results from laboratory smog chamber experiments, as first implemented by Odum et al. $(1996,1997)$ :

VOC + oxidant $\rightarrow \alpha_{1}$ SVOC $_{1}+\alpha_{2} \mathrm{SVOC}_{2}$

where $\alpha_{i}$ are the mass stoichiometric coefficients (mass of product formed per mass of VOC reacted) of two semivolatile lumped products $\mathrm{SVOC}_{i}$, whose partitioning coefficients $\left(\sim 1 / c_{i}^{*}\right)$ are also determined as part of the fit to the smog chamber data. In T models, the vapor pressures of the $\mathrm{SVOC}_{i}$ species change with temperature using a lumped $\Delta H_{\text {vap }}$, which is lower than those for real species due to the lumping effect (Donahue et al., 2006) and the $\mathrm{SVOC}_{i}$ are considered unreactive. Typically $\alpha_{1}+\alpha_{2} \ll 1$. If the total mass of OA to which these $\mathrm{SVOC}_{i}$ can partition is measured or calculated, this approach allows the calculation of the concentrations of SOA products formed from VOC and oxidants measured in ambient air.

In this paper, we model the SOA production from 51 measured VOC (23 aromatics, 13 alkenes and 15 alkanes) using this approach. The model results presented by Volkamer et al. (2006) were calculated with reaction yields and gas-particle partitioning coefficients from Koo et al. (2003). Here we follow the same approach for oxidation products of measured alkenes, alkanes and low yield aromatics, while oxidation products of high yield aromatics are modeled with the parameterization from $\mathrm{Ng}$ et al. (2007), and we refer to this combined approach as the "Updated Traditional SOA model" (UT model). Specifically, Ng et al. (2007) recently revisited the SOA formation from three high-yield aromatics (benzene, toluene and m-xylene) in improved chamber studies, and reported a more detailed aromatic VOC oxidation scheme that considers low- and high- $\mathrm{NO}_{\mathrm{x}}$ products. Briefly, high-yield aromatics such as toluene will form a $\mathrm{RO}_{2}$ radical after formation of an $\mathrm{OH}^{-}$adduct and oxygen addition. The resulting $\mathrm{RO}_{2}$ radical can react via two possible channels, with $\mathrm{HO}_{2}$ (or $\mathrm{RO}_{2}^{-}$) or with $\mathrm{NO}$ :

$\mathrm{RO}_{2}+\mathrm{HO}_{2} \rightarrow \mathrm{ROOH}+\mathrm{O}_{2}$

$\mathrm{RO}_{2}+\mathrm{NO} \rightarrow \mathrm{RO}+\mathrm{NO}_{2}$

The former reaction represents the "low- $\mathrm{NO}_{\mathrm{x}}$ channel," and the latter the "high- $\mathrm{NO}_{\mathrm{x}}$ channel." For the results presented in this paper, the $\mathrm{RO}_{2}$ self-reaction makes a very small contribution, and is thus neglected. The SOA formed from oxidation of each high-yield aromatic under low- $\mathrm{NO}_{\mathrm{x}}$ conditions is parameterized with only one non-volatile SOA product with high yield $(\geq 30 \%)$, while under high- $\mathrm{NO}_{\mathrm{x}}$ conditions SOA formation is represented by two semivolatile products with lower yields $(\sim 10 \%)$. Here, the branching ratio between the low and high- $\mathrm{NO}_{\mathrm{x}}$ channels is determined by calculating the relative rates of the two competing $\mathrm{RO}_{2}$ reactions with the measured $\mathrm{HO}_{2}$ and NO. Note that benzene was not considered to be a SOA precursor in early SOA models (Carter, 1990; Pandis, 1992). This changed after findings of Martin-Reviejo and Wirtz (2005) and benzene started to be considered a low-yield aromatic. In the UT model used in this paper and after findings of $\mathrm{Ng}$ et al. (2007) benzene is considered to be a high-yield aromatic. The parameters of the UT model are summarized in Table SI-1 (http://www.atmos-chem-phys.net/9/5681/2009/ acp-9-5681-2009-supplement.pdf).

The upper left part of Fig. 3 shows the schematic of the UT model partitioning. The mass of species that do not produce SOA in the time scale of chamber reactions is typically ignored in T models. Since traditional models underpredict SOA, it is of interest to keep track of other pools of gasphase organic species, which could possibly result in additional SOA production. Here we rewrite Eq. (6) per unit mass of reacting VOC as:

$$
\begin{aligned}
\text { VOC }+ \text { oxidant } \rightarrow & \alpha_{1} \mathrm{SVOC}_{1}+\alpha_{2} \mathrm{SVOC}_{2} \\
& +\left(1+\alpha_{O}-\alpha_{1}-\alpha_{2}-\alpha_{C}\right) \mathrm{pVOC} \\
& +\alpha_{C} \mathrm{CO}_{\mathrm{x}}
\end{aligned}
$$

where pVOC refers to "product VOC" that do not partition to SOA within time scales of typical chamber experiments, $\alpha_{O}$ 


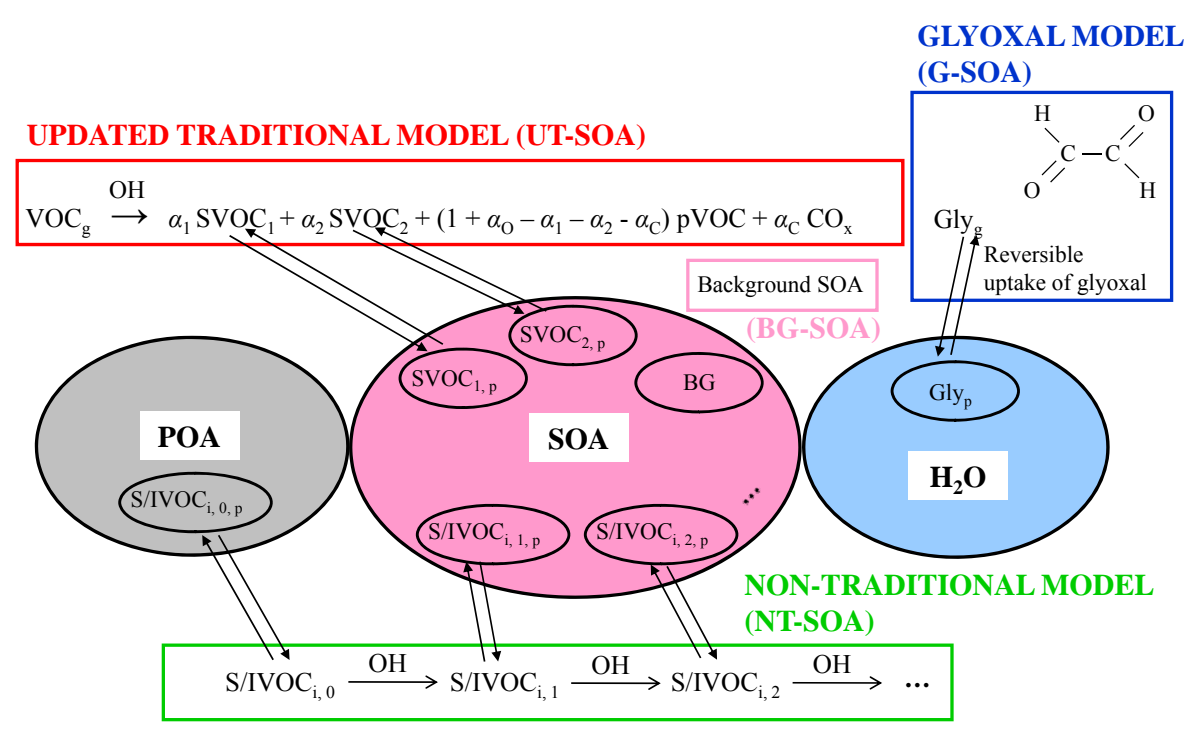

Fig. 3. Scheme of partitioning phases for the base-case model SOA in this study (alternative cases are discussed in Sect. 5.1 and Fig. 15).

accounts for the gain in mass due to the addition of oxygen and nitrogen (and a possible small mass loss from loss of $\mathrm{H}$ due to abstraction by $\mathrm{OH} \cdot$ ) in the reaction products, and $\alpha_{C}$ accounts for the mass of $\mathrm{CO}$ and $\mathrm{CO}_{2}$ (abbreviated as $\mathrm{CO}_{\mathrm{x}}$ ) formed from the VOC oxidation over time scale of chamber experiments. These numbers are poorly constrained in the literature, and in this study we assume $\alpha_{O}=0.2$ and $\alpha_{C}=0.2$, which are in the range of values diagnosed from previous studies (Aumont et al., 2005; Goldstein and Galbally, 2007).

The rate of VOC oxidation at each time step is calculated from the measured VOC and oxidants at that time step, using literature rate constants as:

$\frac{d \mathrm{VOC}}{d t}=k_{\mathrm{OX}}[\mathrm{VOC}]_{t}[\mathrm{OX}]_{t}$

where $k_{\mathrm{OX}}$ is the oxidation rate constant and $\mathrm{OX}=\mathrm{OH}$ or $\mathrm{O}_{3}$. In order to be able to calculate the accumulated products, we discretize the rate equations using a forward finite-difference approach. For a semivolatile species, $\mathrm{SVOC}_{i}$, formed only from the oxidation of a given VOC, we can write:

$$
\begin{aligned}
\frac{d \mathrm{SVOC}_{i}}{d t} & \cong \frac{\Delta \mathrm{SVOC}_{i}}{\Delta t}=\frac{\left[\mathrm{SVOC}_{i}\right]_{t+1}-\left[\mathrm{SVOC}_{i}\right]_{t}}{\Delta t} \\
& =\alpha_{i} k_{\mathrm{OXX}\left[\mathrm{VOC}_{i}\right]_{t}[\mathrm{OX}]_{t}}
\end{aligned}
$$

$\left[\mathrm{SVOC}_{i}\right]_{t+1}=\left[\mathrm{SVOC}_{i}\right]_{t}+\alpha_{i} k_{\mathrm{OX}}\left[\mathrm{VOC}_{i}\right]_{t}[\mathrm{OX}]_{t} \Delta t$

Since the oxidants and the SOA precursors are measured and not calculated, the equation system is not strongly coupled or stiff, and results in a stable solution. A time step of $10 \mathrm{~min}$. is used which is similar to most of the measurements. At each time step, the amounts of UT-SOA (mass of SOA in the

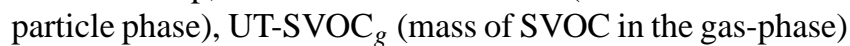
and UT-pVOC are added to the species formed at previous time steps, while accounting for the dilution caused by rising
PBL. The same numerical procedure is used for the models described later.

\subsection{Uptake of gas-phase glyoxal (G-SOA model)}

Glyoxal (CHOCHO) is a first generation oxidation product derived mostly from aromatic VOC but also formed from other VOC such as alkenes (Calvert et al., 2000; Volkamer et al., 2001). Glyoxal has high volatility with a $p_{\text {vap }}=223$ Torr at $20^{\circ} \mathrm{C}\left(c^{*} \sim 10^{9} \mu \mathrm{g} \mathrm{m}^{-3}\right.$; Kielhorn et al., 2004), and has traditionally been assumed to not partition to the particle-phase. However, a number of laboratory (e.g. Liggio et al., 2005a; Kroll et al., 2005a), and modeling (Barsanti and Pankow, 2005) studies have indicated that glyoxal can form SOA. Volkamer et al. (2007a) demonstrated that a SOA source from glyoxal is needed to balance glyoxal sources and sinks in Mexico City, and quantified SOA formation from glyoxal during the MCMA-2003 field campaign.

Volkamer et al. (2007a) modeled glyoxal uptake to the particle-phase with three different models: i) $\mathrm{MCM}_{\gamma}$ which parameterizes an irreversible glyoxal sink to the PM surface; ii) $\mathrm{MCM}_{\text {Peff }}$ which reversibly partitions glyoxal to the measured AMS OOA; iii) MCM $_{\text {Heff }}$ which reversibly partitions gas-phase glyoxal into aerosol liquid water (ALW) according to Henry's Law with an effective constant:

$H_{\text {eff }}=\rho \times H$

where $\rho$ is the aqueous phase activity coefficient, and $H$ is the physical solubility of glyoxal in water $\left(H=5 \mathrm{M} \mathrm{atm}^{-1}\right)$ (Schweitzer et al., 1998). ALW was predicted by a Markov Chain Monte Carlo implementation of the ISORROPIA thermodynamic equilibrium model from aerosol inorganic species and gas-phase ammonia (San Martini et al., 2006). All three models produced similar amounts of G-SOA. In this 
paper, we use the results of $\mathrm{MCM}_{\mathrm{Heff}}$ model as the formation of SOA from glyoxal appears to be dominated by uptake into the aerosol aqueous phase and enhanced with reactions with water soluble organic species (Volkamer et al., 2009).

While much of the glyoxal accounted for here is formed from aromatic oxidation, we believe that the inclusion of a separate mechanism for SOA formation from this species is not double-counting SOA that is already parameterized in the UT SOA chamber experiments, for the following reasons: (a) the chamber experiments of $\mathrm{Ng}$ et al. (2007) were conducted under dry conditions with an inorganic seed; (b) most of the SOA products identified from aromatic systems to date at the molecular level are unrelated to glyoxal (Yu et al., 1995; Forstner et al., 1997; Cocker et al., 2001); (c) AMS mass spectra of aromatic SOA formed in the presence of aqueous ammonium-sulfate seed in chamber experiments (Bahreini et al., 2005) differ from the mass spectra of SOA generated from glyoxal uptake to ammonium-sulfate (Liggio et al., 2005b). For a more detailed discussion of this point see Volkamer et al. (2009).

\subsection{Non-traditional SOA model (NT model)}

Almost all regional and global models treat POA as nonvolatile. However, Lipsky and Robinson (2006) showed that POA is semivolatile and that its gas-particle partitioning is governed by absorptive partitioning theory and thus will mainly depend on temperature and on the amount of pre-existing organic aerosols. Huffman et al. (2009a) have recently confirmed the semivolatile character of fresh POA (identified as HOA) in Mexico City using a thermodenuderAMS combination. Robinson et al. (2007) apportioned POA from diesel exhaust and wood burning into the "volatility basis set" framework of Donahue et al. (2006) classifying the organic compounds emitted as (a) "non-volatile" compounds (NVOC) that are always in the particle phase under ambient conditions; (b) semivolatile compounds (SVOC) that partition between the gas and particle phases between emission and ambient conditions; and (c) intermediate volatility compounds (IVOC) which are always in the gas-phase under emission and ambient conditions, but are less volatile than traditional VOC species such as aromatics and may play an important role in SOA formation. Here we implement the primary SVOC and IVOC model (abbreviated from Non-Traditional SOA model as "NT model") exactly as described by Robinson et al. (2007) and as shown in Table SI-2 (http://www.atmos-chem-phys.net/9/5681/2009/ acp-9-5681-2009-supplement.pdf). Note that we assume that all POA is represented by the S/IVOC distribution determined by Robinson et al. (2007) for diesel exhaust (which is similar to that determined by wood burning by the same authors). Although this introduces some uncertainty, it is the only reasonable assumption that can be made, since the volatility distributions of other POA types have not been reported.
The NT model can be represented with a series of equations as:

$\mathrm{S} / \mathrm{IVOC}_{i, j, g}+\mathrm{OH} \rightarrow \mathrm{S} / \mathrm{IVOC}_{i, j+1, g}$

$\mathrm{S} / \mathrm{IVOC}_{i, j+1, g} \leftrightarrows \mathrm{S} / \mathrm{IVOC}_{i, j+1, p}$

where $i=1-9$ and refers to 9 initial volatility bins described by Robinson et al. (2007), $j$ is an integer $\geq 0$ and is equal to the generation of the oxidation products from primary emitted S/IVOC ( $j=0$ for primary emitted S/IVOC), and $g$ and $p$ refers to gas- and particle-phase, respectively. Once emitted, those primary S/IVOC of different volatilities (S/IVOC $i, 0, p+g$ ) will quickly reach gas-particle equilibrium at a given ambient temperature and POA concentration. For example, at $20^{\circ} \mathrm{C}$ and $10 \mu \mathrm{g} \mathrm{m}^{-3}$ of POA concentration, $87 \%$ of the total primary S/IVOC mass $\left(77 \mu \mathrm{g} \mathrm{m}^{-3}\right)$ will be in the gas-phase when using the model parameters of Robinson et al. (2007) (Table SI-3). The directly emitted S/IVOC (S/IVOC $i, 0, g$ in Eq. 14) react with $\mathrm{OH}^{-}$in the gas-phase and give products of lower volatility that will partition more towards the particle-phase $\left(\mathrm{S}_{\mathrm{IVOC}} \mathrm{IV}_{i, g}\right.$ in Eq. 15). Robinson et al. (2007) assumed that each $\mathrm{OH}^{-}$reaction reduces the saturation concentration by an order-ofmagnitude, and that all gas-phase species react with $\mathrm{OH}^{-}$ with $k_{\mathrm{OH}}=4 \times 10^{-11} \mathrm{~cm}^{3}$ molec $^{-1} \mathrm{~s}^{-1}$. This results in a time scale of about $2 \mathrm{~h}$ per generation for the $\mathrm{OH}^{-}$levels shown in Fig. 1. In this way, the initial S/IVOC $i, 0, g$ can undergo multiple generations of oxidation and each generation of products has lower volatility than their parent S/IVOC. This implementation also assumes that each $\mathrm{OH}^{-}$reaction adds $7.5 \%$ of oxygen mass to the resulting product mass. Although it is known that gas-phase organic reactions can lead to bond scission (Kroll and Seinfeld, 2008), this mechanism assumes that no VOC of higher volatility, $\mathrm{CO}$, or $\mathrm{CO}_{2}$ are formed, which if taken into account would reduce the amount of SOA formed. Another structural uncertainty of the NT model is the lack of particle-phase accretion reactions (e.g. Barsanti and Pankow, 2005), which if included would increase the amount of model SOA produced. According to this mechanism, $\mathrm{S} / \mathrm{IVOC}_{i, j, p}$ do not react while in the particle-phase (Robinson et al., 2007).

A critical step of this model is to estimate the amounts of the different P-S/IVOC present in ambient air during our case study. Robinson et al. (2007) performed laboratory chamber experiments and measured Q-AMS spectra of diluted diesel exhaust before and after initiating photochemical oxidation. They found that non-oxidized spectra of freshly emitted primary emissions (POA) is very similar to reference AMS HOA spectra, while SOA made in the experiment is quite similar to reference AMS OOA. Based on this finding we implement the Robinson et al. (2007) NT model using the measured HOA (a surrogate for POA, see Sect. 2.1) at each time bin (10 min) and the estimated height of PBL vs. time (Fig. SI-3, http://www.atmos-chem-phys. 
net/9/5681/2009/acp-9-5681-2009-supplement.pdf). We estimate the POA emission per time bin $\left(\Delta \mathrm{HOA}_{t}\right.$, in $\left.\mu \mathrm{g} \mathrm{m}^{-3}\right)$ by applying mass conservation in the expanding box volume as:

$\Delta \mathrm{HOA}_{t}=\mathrm{HOA}_{t}-\mathrm{HOA}_{t-1} * \frac{\mathrm{PBL}_{t-1}}{\mathrm{PBL}_{t}}$

where HOA $\left(\mu \mathrm{g} \mathrm{m}^{-3}\right)$ is measured and PBL $(\mathrm{m})$ is constrained as discussed above. The measured HOA has a background of $\sim 1.7 \mu \mathrm{g} \mathrm{m}^{-3}$ at midnight (Fig. SI3d, http://www.atmos-chem-phys.net/9/5681/2009/ acp-9-5681-2009-supplement.pdf). To reduce the effect of noise and short time-scale oscillations on Eq. (16), the POA emissions are estimated from an interpolated profile which captures the diurnal behavior of measured HOA (Fig. SI-3d).

To calculate the amount of primary gas-phase material emitted together with the HOA, we assume equilibrium gas/particle partitioning of the $\mathrm{S} / \mathrm{IVOC}_{j, 0, g+p}$ species distribution of Robinson et al. (2007) with the total HOA present (Table SI-2). As shown in Table SI-3 and discussed later, this introduces a large amount of P-S/IVOC, which is several times the POA emission. The kinetic equations for the PS/IVOC species are solved by the same techniques described in the previous section.

Sheehy et al. (2008) have recently evaluated whether the introduction of additional gas-phase organic species as estimated here is compatible with measurements of the $\mathrm{OH}$ reactivity in Mexico City during MCMA-2003. The $\mathrm{OH}^{\circ}$ reactivity calculated from all measured species underpredicts the directly-measured $\mathrm{OH}^{-}$reactivity, with the gap between calculated and observed reactivity being the largest during the morning rush hour. The additional reactivity from the estimated P-S/IVOC is consistent with the observed reactivity gap, but is insufficient to obtain closure. A comparison of the intensity of total gas-phase C-H stretches in long path FTIR measurements is also consistent with this conclusion: a gap between the total and calculated $\mathrm{C}-\mathrm{H}$ stretched is observed, and the estimated C-H stretches from the S/IVOC is smaller than the observed gap (Volkamer et al., unpublished data). Thus we conclude that the introduction of additional mass from P-S/IVOC is not inconsistent with our current knowledge and constraints for VOC chemistry in Mexico City. Given that the P-S/IVOC do not fully close the gap between the observed and modeled $\mathrm{OH}$ reactivity and $\mathrm{C}-\mathrm{H}$ stretches, additional organic species are available for oxidation beyond those considered here.

The implementation of P-S/IVOC emission and aging has enabled us to easily simulate possibly thousands of new S/IVOC species that were previously not considered in SOA models, which provides a valuable comparison to the amount of SOA formed with other models and to the ambient measurements. However major uncertainties remain on the specifics of this model, that require further attention by the scientific community. While the amount of SVOC is con- strained by dilution experiments for two types of sources, Robinson et al. (2007) also introduce the lumped IVOC species ( $c *$ in range $10^{4}-10^{6} \mu \mathrm{g} \mathrm{m}^{-3}$ ). The amount of IVOC mass specified by Robinson et al. (2007) is $1.5 \times$ SVOC mass, with an estimated uncertainty range from $1-3 \times$ SVOC. Furthermore, the proposed gas-phase S/IVOC oxidation mechanism may require further refinement. For example, the $\mathrm{OH}^{-}$ reaction rates, gain of oxygen upon oxidation, and formation of more volatile $\mathrm{VOC}$ or $\mathrm{CO}, \mathrm{CO}_{2}$, need to be better constrained experimentally. The sensitivities of the NT model to some of the above uncertain parameters are evaluated in Sect. 5 below.

One S/IVOC system which has been characterized very recently in the laboratory is the formation of SOA from naphthalene, 1- and 2-methylnaphthalene, and dimethylnapthalane (Chan et al., 2009). In our model these species are treated as high-yield aromatics as part of the UT-model, while the yields of Chan et al. for high- $\mathrm{NO}_{\mathrm{x}}$ conditions are about 3 times larger than those used here. From the reported ratios of these species to $\mathrm{CO}$ in the the rush hour in Mexico City (Flores et al., 2004; Marr et al., 2006; J. Arey, F. Reisen, and $\mathrm{H}$. Bethel, unpublished data) and the yields of Chan et al. (2009) we estimate that the naphthalene family would produce about $0.35 \mu \mathrm{g} \mathrm{m}^{-3}$ of SOA per ppm of CO, which represents about $1 \%$ of the SOA observed in the afternoon as shown in Fig. 2 above. Thus since the impact is very minor we have not included the updated yields for the naphthalene family in our calculations.

Finally, there is some debate about whether the NT-SOA formed from this mechanism should be referred to as oxidized POA (OPOA) (Shrivastava et al., 2008). We prefer to retain the term SOA since in this mechanism the species react in the gas-phase and the subsequent reduction in volatility leads to increasing partitioning into the particle phase, in accordance with the traditional definition of SOA. We also note that the IVOC were never part of the POA, even under the most concentrated conditions after cooling of the emissions (Robinson et al., 2007), and thus it would be undeniably wrong to refer to the SOA formed from these species as OPOA. Rather the SOA formed from S/IVOC fits the traditional definition of SOA but arises from volatile and semivolatile precursors that were ignored in previous models.

\subsection{Partitioning phases for organics in our study}

To calculate the gas-particle partitioning of VOC oxidation products in the UT and NT models, the amount of organic aerosols available for partitioning at each time step is needed ( $c_{\mathrm{OA}}$ in Eq. 1). Volkamer et al. (2006) estimated an upper limit for model SOA, and thus used the total AMS measured $\mathrm{OA}(\mathrm{OOA}+\mathrm{HOA})$ as the $c_{\mathrm{OA}}$ available for partitioning. This approach showed conclusively that $\mathrm{T}$ models could not reproduce the observations from this case study even under the most favorable case of a very large partitioning mass. In this 


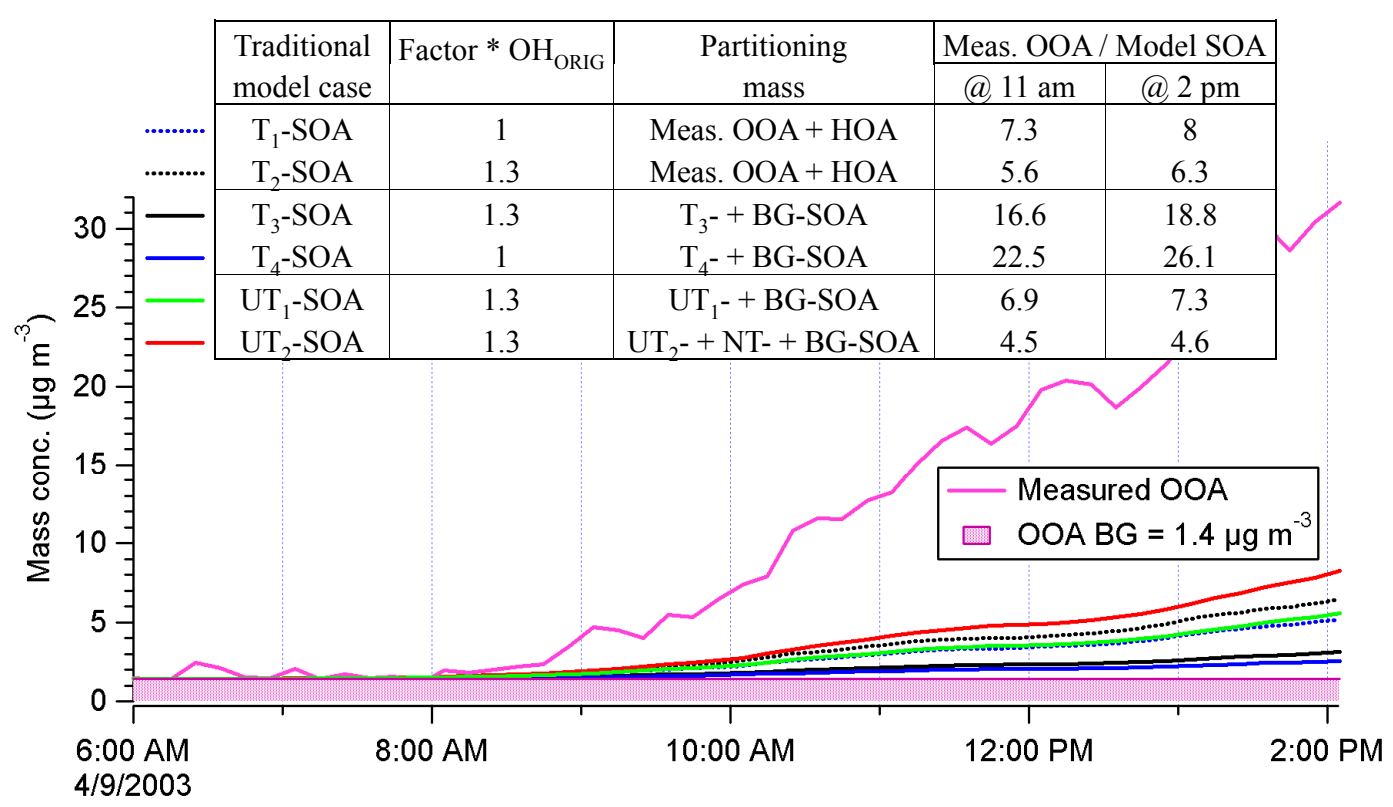

Fig. 4. Comparison of SOA formed in different runs of the T and UT models vs. measured OOA. The table shows the assumptions of each model run. See text for details.

study we calculate partitioning into the model OA instead, which is a more realistic scenario, since when applying SOA modules in regional and global models the OA mass available for partitioning is that predicted by the model. In addition, Song et al. (2007) recently showed that in laboratory chamber experiments the presence or absence of POA surrogates did not influence the amount of freshly formed SOA from $\alpha$-pinene ozonolysis. These authors suggest that the very different chemical nature of SOA (highly oxygenated) vs. POA (very reduced) leads to high activity coefficients of SOA in the POA phase, resulting in very small partitioning. Although these results need to be confirmed for other precursors and using real POA, it is likely that the HOA measured by the AMS in Mexico City does not offer a favorable phase for partitioning of freshly formed SOA given their very different oxygen content (Aiken et al., 2008). To provide a more realistic comparison of model performance with measurements, in this paper we use the total model-predicted SOA (plus the preexisting background OOA) as the partitioning phase for model SOA. We consider alternative partitioning assumptions as sensitivity case studies below.

Figure 3 and Table 1 present a schematic of the basecase partitioning phases used for all model species in this study. The base-case model is composed of three partitioning phases: POA, SOA and water. The UT model condensable species, UT-SVOC ${ }_{g+p}$, are assumed to partition only to the SOA phase. The primary emitted S/IVOC partition only to the POA phase. The secondary S/IVOC formed from oxidation of the P-S/IVOC and further generations of oxidation are assumed to partition only to the SOA phase. We also include in the SOA phase the background SOA (BG-
SOA) defined from the pre-existing background OOA measured by the AMS before the start of the photochemistry $\left(\sim 1.4 \mu \mathrm{g} \mathrm{m}^{-3}\right)$, and assume that this BG-SOA is constant throughout the measurement period, i.e. it is also present in the dilution air mixed in during the growth of the PBL, which is likely an upper limit as described above. Finally, glyoxal is assumed to partition only into the aqueous phase. The sensitivity of the model to these simplified partitioning assumptions is evaluated below in Sect. 5.1.

In the numerical implementation, the amount of SOA present at each time step is calculated by iteration. Starting with the $c_{\mathrm{SOA}}$ from the previous time step, the new partitioning after formation of additional SVOC, dilution, and temperature change is calculated. This leads to a change in $c_{\mathrm{SOA}}$. In the next iteration, the partitioning of all SOA species is recalculated into the new $c_{\mathrm{SOA}}$, and the procedure is repeated until the change in $c_{\mathrm{SOA}}$ between successive iterations is smaller than $0.1 \%$.

\section{Results and discussion}

\subsection{Updated traditional SOA model results (UT model)}

The results from six variations of the $\mathrm{T}$ and UT models are shown in Fig. 4, while the parameters of the models are summarized in Table 1. We compare the SOA produced by the model to the observed increase of OOA above the early morning background OOA mass. The original T-SOA modeled in Volkamer et al. (2006) is shown for reference, and accounts for $\sim 12 \%$ of measured increase in OOA mass above the early morning background $\left(\mathrm{T}_{1}\right.$-SOA case). We 
Table 1. Partitioning phases for the base case of our study and for the Volkamer et al. (2006) study. The effect of alternative partitioning assumptions is explored in Sect. 5.1. (BG-OOA $=$ Background OOA=1.4 $\mu \mathrm{g} \mathrm{m}^{-3}$ ). $\sqrt{ }$ means that the activity coefficient $\zeta=1$.

\begin{tabular}{|c|c|c|c|c|c|c|}
\hline & AMS HOA (meas.) & AMS OOA (meas.) & Water & UT-SOA & G-SOA & NT-SOA \\
\hline $\mathrm{T}_{1}$ - and $\mathrm{T}_{2}$-SOA (Volkamer et al., 2006) & $\sqrt{ }$ & $\sqrt{ }$ & & & & \\
\hline $\mathrm{T}_{3}$ - and UT-SOA (this study) & & $\sqrt{ }($ Only to BG-OOA $)$ & & $\sqrt{ }$ & & $\sqrt{ }$ \\
\hline G-SOA & & & $\sqrt{ }$ & & & \\
\hline NT-SOA & & $\sqrt{ }($ Only to BG-OOA $)$ & & $\sqrt{ }$ & & $\sqrt{ }$ \\
\hline
\end{tabular}

first evaluate the effect of the increase in measured $\mathrm{OH}$ (see Sect. 2.1) using the same model setup and assumptions as Volkamer et al. (2006), which we refer to as $\mathrm{T}_{2}$-SOA. Both $\mathrm{T}_{1}$-SOA and $\mathrm{T}_{2}$-SOA models partition the model SOA to total measured OA (Table 1). There is a $\sim 28 \%$ average increase in T-SOA produced with the $30 \%$ higher $\mathrm{OH}$ which represents $16 \%$ of the measured OOA and is far from closing the gap.

For comparison with the results of this paper, we also ran a more realistic version of the Volkamer et al. (2006) T-SOA model, assuming that the T-SOA partitions only into the BGSOA and T-SOA (with the updated higher $\mathrm{OH}^{-}$). This is the $\mathrm{T}_{3}$-SOA case in Fig. 4. The reduction of partitioning mass results in a large reduction of the predicted SOA formed with respect to the Volkamer et al. (2006) results, which is only

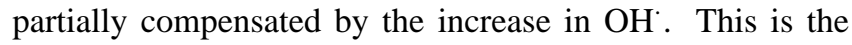
most realistic run of the $\mathrm{T}$ model for this case study, which on average produces less than half of the SOA modeled by Volkamer et al. (2006), and is $\sim 19$ times too low when compared to observations. Thus the factor of $\sim 8$ reported by Volkamer et al. (2006) was a very conservative estimate of the SOA underprediction by the T model vs. the factor of $\sim 26$ ( $\mathrm{T}_{4}$-SOA case) that would have been obtained with the $\mathrm{OH} \cdot$ concentrations specified at the time.

Two cases are computed using the UT-SOA model which replaces the Koo et al. (2003) parameterization for high-yield aromatics with the $\mathrm{Ng}$ et al. (2007) one. In the first case $\left(\mathrm{UT}_{1}\right.$-SOA) we aim to provide a direct quantification of the effect of this change and assume that the UT-SOA partitions into the $\mathrm{BG}-\mathrm{SOA}+\mathrm{UT}_{1}-\mathrm{SOA}$, which can be compared directly to the $\mathrm{T}_{3}$-SOA model prediction. The effect of updating the aromatic mechanism is to reduce the measured-tomodel ratio at 2 p.m. from $\sim 19$ to $\sim 7$, leading to explaining $14 \%$ of the measured SOA. The results of the $\mathrm{UT}_{1}$ model are remarkably similar to those from the $\mathrm{T}_{1}$ model used in the Volkamer et al. (2006) paper. This indicates that the various effects compensate each other in the model. Thus a major discrepancy still exists, and the new yields for aromatic SOA are far from closing the gap for our case study.

We then compute the contribution of the updated mechanism to the overall base case as shown in Fig. 3 (UT ${ }_{2}-$ SOA), that uses all available model SOA mass (BGSOA+UT-SOA+NT-SOA) for partitioning of the UT-SOA.
The availability of a large amount of extra partitioning mass from the NT-SOA model results in a significant increase in model-predicted SOA compared to case $\mathrm{UT}_{1}$ SOA $(\times 1.6)$. With these assumptions the UT model explains $\sim 22 \%$ of the measured SOA mass, and represents the base-case for the UT model in later sections of this paper. The time dependence of measured OOA and the predicted SOA from all implementations of the T and UT models is very similar (Fig. SI-4, http://www.atmos-chem-phys.net/ 9/5681/2009/acp-9-5681-2009-supplement.pdf) suggesting that whichever precursors are producing most of measured SOA are doing so on time scales similar to the firstgeneration products of aromatics, consistent with the results of Volkamer et al. (2006).

The speciation of the $\mathrm{UT}_{2}-\mathrm{SOA}$ and $\mathrm{UT}_{2}-\mathrm{SVOC}_{g}$ products is shown in Fig. 5. Most SOA mass $(\sim 85 \%)$ arises from oxidation of high-yield aromatics under high- $\mathrm{NO}_{\mathrm{x}}$ conditions (Fig. 5a). In this case study the overwhelming majority of the $\mathrm{RO}_{2}(>99 \%)$ radicals react with $\mathrm{NO}$ according to the $\mathrm{Ng}$ et al. (2007) formulation (Fig. SI-5). The low-NO $\mathrm{N}_{\mathrm{x}}$ channel on average produces only $\sim 0.6 \%$ of the UT-SOA, despite the very high yields of this channel. The product SVOC remaining in the gas-phase are dominated by the high-volatility products of high-yield aromatic oxidation, which make up $\sim 95 \%$ of the gas-phase SVOC mass (Fig. 5b). The measured OOA is several times larger than total SVOC (SOA + gas SVOC) mass in this model, indicating that even if all UTSVOC mass would partition to particle phase and form SOA, the UT-SOA would still be too small to explain measured SOA by a factor of 3.1.

The UT-SOA fraction arising from the oxidation of nominally biogenic VOC (isoprene and terpenes) during our case study is $\sim 2 \%$ of the total UT-SOA. We also note that a recent modeling study concludes that the isoprene observed in Mexico City is most likely of anthropogenic origin, and that the small amount of biogenic SOA which may impact Mexico City is formed away from the city and advected in, and thus is not relevant during our case study (Hodzic et al., 2009). Wildfires and agricultural fires were very low in the period around 9 April 2003 and would be unlikely to reach our site in the morning due to low wind speeds (see Sect. SI-2, http://www.atmos-chem-phys.net/9/ 5681/2009/acp-9-5681-2009-supplement.pdf). Based these 


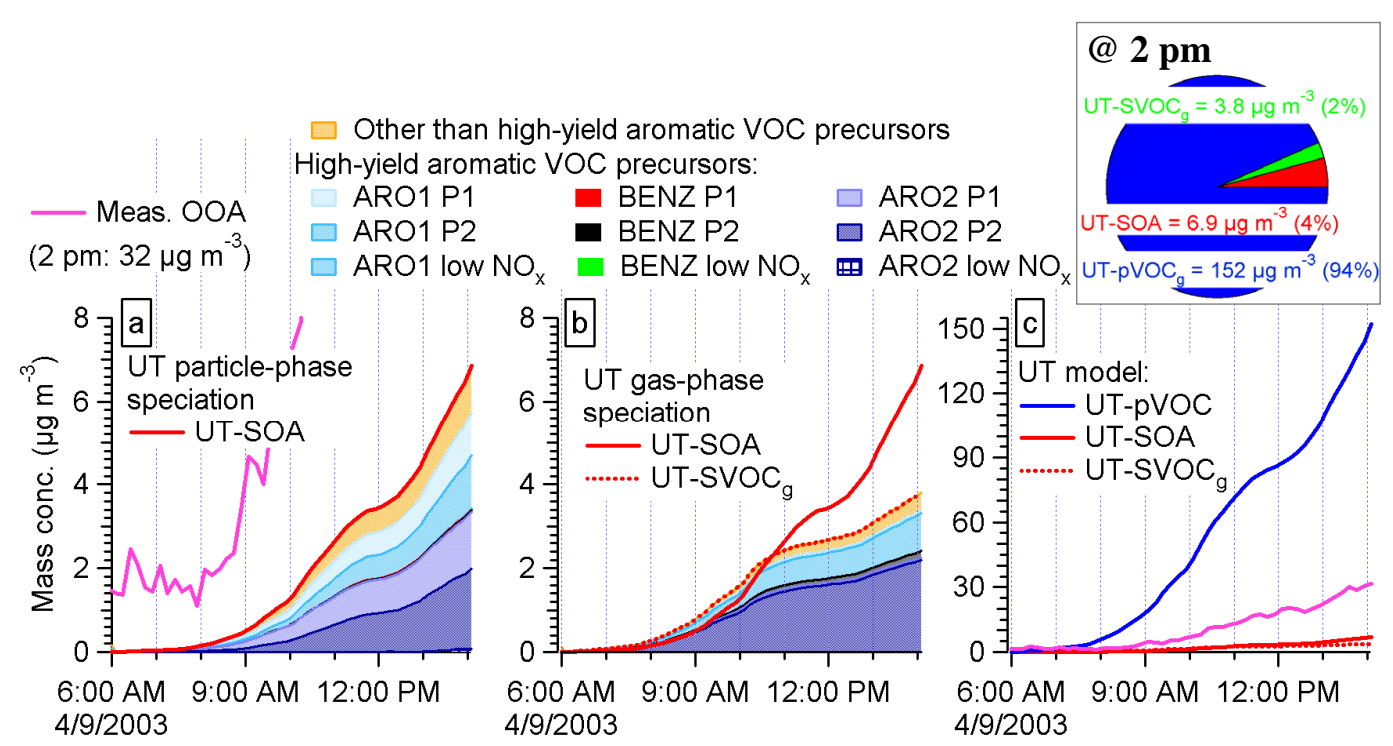

Fig. 5. speciation of UT model results. Panel (a) shows total UT-SOA divided in its contributing SOA species. Panel (b) shows total UT-SVOC $_{g}$ divided in its contributing gas SVOC species. The lower most panel (c) shows all gas- and particle-phase organic species formed in UT model (UT model total = UT-SOA + UT-SVOC $g$ + UT-pVOC). See Fig. SI-6 (http://www.atmos-chem-phys.net/9/5681/2009/ acp-9-5681-2009-supplement.pdf) for an alternative representation of this speciation.

arguments, the low levels of BB tracers described in Supp. Info Sect. 2, and the absence of a BB factor when running PMF for this period alone (PMF can generally retrieve factors from AMS datasets whose average mass fraction is above 5\%; Ulbrich et al., 2009), we estimate that BBOA from non-urban burning contributed less than 5\% to OA during our case study. However, some of the measured hydrocarbons could be from urban sources such as food cooking and trash burning, and thus some of the UT-SOA may be derived from modern carbon sources. Similarly if some of the HOA arises from modern sources, some of the S/IVOC should contribute modern carbon to the NT-SOA. Finally, for similar reasons some of the glyoxal may arise from modern sources of anthropogenic VOC. Overall the sum of these sources may contribute significantly to the modern carbon $\left({ }^{14} \mathrm{C}\right)$. Unfortunately no ${ }^{14} \mathrm{C}$ aerosol measurements are available for our case study. The evaluation of the consistency between highly time-resolved studies and modern carbon-based studies have already been highlighted as a key focus of future research (Hallquist et al., 2009; de Gouw and Jimenez, 2009), and an attempt should be made to perform ${ }^{14} \mathrm{C}$ measurements with as high time resolution as possible and at the same location as the highly time-resolved VOC, oxidant, and aerosol measurements in order to reduce ambiguities in the interpretation of the ${ }^{14} \mathrm{C}$ data.

A potential source of additional organic mass which could help close the gap between model and measurements is the product VOC (pVOC), described in Sect. 3.3 as the nonpartitioning gas-phase products of the oxidation of VOC considered in the UT model. Figure 5c shows that UT-pVOC comprise by far the largest fraction of the mass arising from the reaction of these VOC precursors. Although some of these UT-pVOC (such as e.g. formaldehyde) are unlikely to form SOA, others may be able to do so upon further oxidation on time scales longer than available in chamber studies, or through particle-phase accretion reactions with species not available in traditional chamber studies (e.g. Volkamer et al., 2009). One example of a pVOC that forms SOA is glyoxal, as described below. Due to very large amount of UT-pVOC, unrecognized SOA formation from pVOC with a yield of a few percent could explain a significant fraction of the measured SOA. Note that the pVOC calculated here do not include the gas-phase products of species which are not included in traditional SOA models (Koo et al., 2003) such as hexane, and these species would produce an additional amount of $\mathrm{pVOC}$ which could possibly participate in SOA formation through accretion reactions, providing an additional route to SOA formation.

We can estimate the order-of-magnitude of additional gasphase organics beyond those included in pVOC using the results of Heald et al. (2008) who reported the total observed organic carbon (TOOC) inside Mexico City to be about 37 times the particle-phase OC concentration. The total organics included in the UT model (SOA, SVOC, and pVOC) are about 5 times the measured aerosol concentration, which is increased to $\times 7.5$ if all the species included in the G-SOA and NT-SOA models (reported below) are included as well. Thus we estimate that only $20 \%$ of the total organic species present in Mexico City's atmosphere are accounted for in any of the models considered in this paper, which underscores 

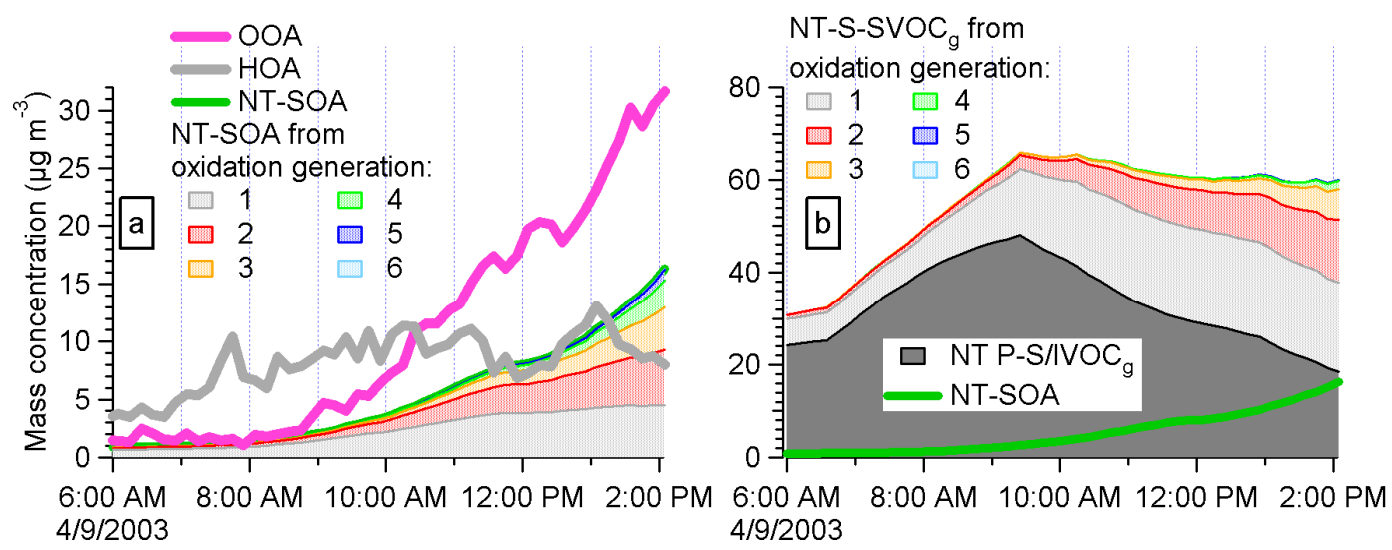

Fig. 6. Speciation of NT-SOA. Panel (a) shows the contributions of SOA formed in each one of six generations of oxidation of P-S/IVOC to the total NT-SOA. Panel (b) shows the contributions to gas-phase NT-S-SVOC $g$ from six generations of oxidation.

the additional potential for SOA formation from the additional $80 \%$ of organic species. This group is dominated by species such as butane, propane, acetone etc. that have not been traditionally considered to produce SOA. However the recent discovery that even acetylene $\left(\mathrm{C}_{2} \mathrm{H}_{2}\right)$ can produce SOA (Volkamer et al., 2009) raises the question of whether SOA formation from some of these species, although with a very low yield, could also contribute significantly to ambient SOA concentrations, given their large concentrations.

An alternative representation of the speciation of all UT model products at 2 p.m. during this case study is shown in Fig. SI-6 (http://www.atmos-chem-phys.net/9/5681/2009/ acp-9-5681-2009-supplement.pdf). This illustrates again the dominance of aromatic products in SOA and product SVOC, but the comparable importance of the other precursors as sources of $\mathrm{pVOC}$.

To illustrate the representativeness of our case study, we show in Fig. SI-7 the measured OOA and the simulated $\mathrm{T}_{3}-$ SOA and $\mathrm{UT}_{1}$-SOA for four other days during MCMA-2003. Although these days are less ideal for the type of modeling pursued here due to higher background and higher meteorological dilution, the result of a large underestimate of SOA by the T and UT models is similar to that in our case study.

\subsection{Glyoxal SOA model results (G model)}

The results of G model in our base case are the same as those

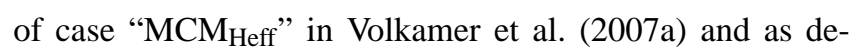
scribed in Sect. 3.3. Briefly, glyoxal is produced in the MCM model mostly from $\mathrm{OH}^{\circ}$ oxidation of aromatic $\mathrm{VOC}(\sim 75 \%)$, and the other two significant contributions are $\mathrm{O}_{3}$ oxidation of alkenes $(\sim 15 \%)$ and $\mathrm{OH}^{\circ}$ oxidation of acetylene $(\sim 10 \%)$. The modeled gas-phase glyoxal is 2-6 times higher than the direct DOAS measurements, with the difference increasing as the day progresses. The model predicts significantly more gas-phase glyoxal than measured by DOAS during MCMA2003, which can be explained by an additional glyoxal sink which is parameterized as described above. The amount of G-SOA modeled explains $\sim 17 \%$ of the AMS OOA, and is comparable to the amount of UT-SOA. The timing of G-SOA increase is also similar to that of the OOA.

\subsection{Non-traditional SOA model results (NT model)}

Figure 6 shows the results of the NT model for our case study. The total NT-SOA formed by this mechanism is larger than the combined UT-SOA and G-SOA. OH concentrations are high which allows five generations of oxidation products to contribute to model SOA by the end of the case study at 2 p.m. (Fig. 6a). With the parameters of Robinson et al. (2007) and the implementation assumptions used here, this SOA model introduces a large amount of gasphase organics with high SOA yield and potentially closes the SOA gap as described below. In our case study the total amount of NT-P-S/IVOC introduced is 7.5 time the estimated HOA emissions (mass-weighed average over the case study), which is the same as factor assumed by Tsimpidi et al. (2009). Figure $6 \mathrm{~b}$ shows the primary gas-phase S/IVOC and their gas-phase oxidation products. The amount of secondary gas SVOC (not including the primary species) is more than double $(\times 2.6)$ the amount of SOA at 2 p.m. The gasphase SVOC in this mechanism will undergo further generations of oxidation which will continuously decrease their volatility and eventually end almost completely in the SOA phase. Thus they carry a potential for much more SOA formation with increased aging. The structure of this model contrasts strongly with the UT model, where no further oxidation or volatility reduction occurs after the reaction of the original VOC.

Gas- and particle-phase mass in NT model can be grouped by several different parameters (Table 2): generation of oxidation of the primary emitted material, saturation concentration, $c *$, and the volatility bin of primary emitted material. Figure SI-8 shows the mass distribution of NT-SOA 

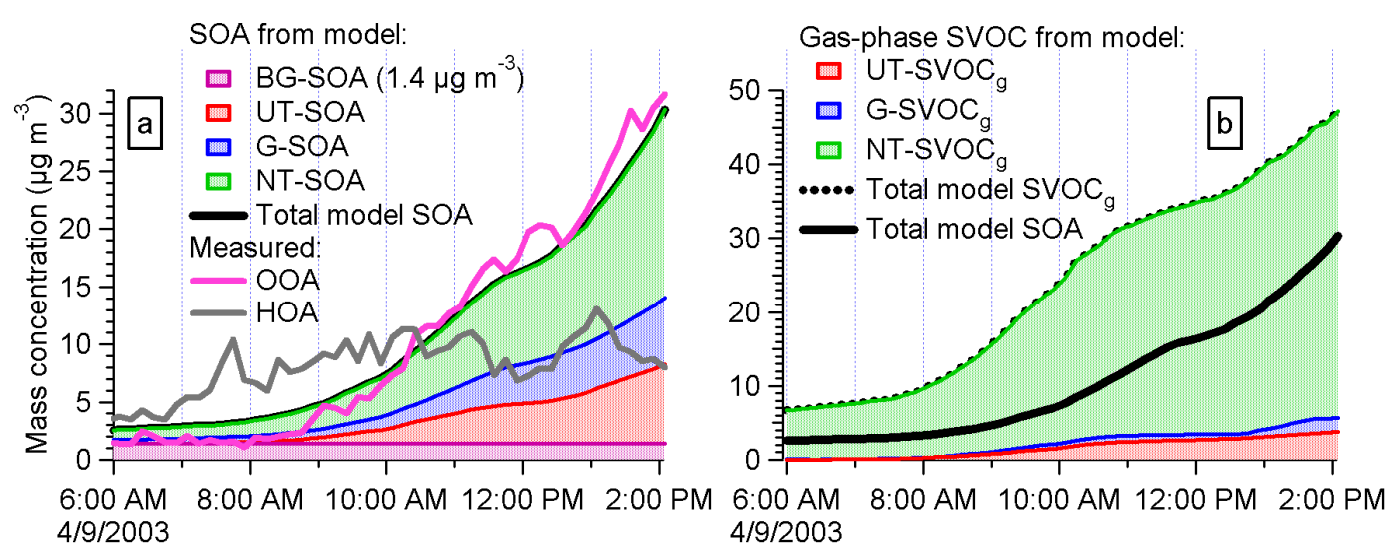

Fig. 7. Total model SOA and gas SVOC for the base case of this paper. Panel (a) shows the contributions of each model to the total model SOA, and panel (b) shows the contributions to the total model gas-phase SVOC.

Table 2. The mass in NT model is grouped by several possible parameters: a) the generation of oxidation, $j$; b) the saturation concentration, $c *$; and c) the initial volatility bin, $i$. Every bin is represented with the appropriate $c^{*}\left(\mu \mathrm{g} \mathrm{m}^{-3}\right)$. Note that the primary emitted material is shown as bold and italic, and will not be included in the secondary produced mass. The generation of oxidation, $j$, of primary emitted and secondary produced mass is abbreviated as $\mathrm{G} j$, where $j=0-6$.

\begin{tabular}{|c|c|c|c|c|c|c|c|c|c|c|}
\hline \multicolumn{11}{|c|}{ Same saturation concentration, $c^{*}$} \\
\hline \multirow{8}{*}{$\begin{array}{l}\text { Same generation } \\
\text { of oxidation, } j\end{array}$} & $\begin{array}{ll}i \\
j\end{array}$ & 1 & 2 & 3 & 4 & 5 & 6 & 7 & 8 & 9 \\
\hline & G0: P-S/IVOC $C_{i, 0, p+g}$ & $10^{-2}$ & $10^{-1}$ & 1 & 10 & $10^{2}$ & $10^{3}$ & $10^{4}$ & $10^{5}$ & $10^{6}$ \\
\hline & G1: S-S/IVOC $\mathrm{i}_{\mathrm{i}, \mathrm{p}+\mathrm{g}}$ & $10^{-3}$ & $10^{-2}$ & $10^{-1}$ & 1 & 10 & $10^{2}$ & $10^{3}$ & $10^{4}$ & $10^{5}$ \\
\hline & G2: S-S/IVOC $\mathrm{i}_{\mathrm{i}, 2, \mathrm{p}+\mathrm{g}}$ & $10^{-4}$ & $10^{-3}$ & $10^{-2}$ & $10^{-1}$ & 1 & 10 & $10^{2}$ & $10^{3}$ & $10^{4}$ \\
\hline & G3: S-S/IVOC $\mathrm{i}_{\mathrm{i}, 3, \mathrm{p}+\mathrm{g}}$ & $10^{-5}$ & $10^{-4}$ & $10^{-3}$ & $10^{-2}$ & $10^{-1}$ & 1 & 10 & $10^{2}$ & $10^{3}$ \\
\hline & G4: S-S/IVOC ${ }_{\mathrm{i}, 4, \mathrm{p}+\mathrm{g}}$ & $10^{-6}$ & $10^{-5}$ & $10^{-4}$ & $10^{-3}$ & $10^{-2}$ & $10^{-1}$ & 1 & 10 & $10^{2}$ \\
\hline & G5: S-S/IVOC ${ }_{\mathrm{i}, 5, \mathrm{p}+\mathrm{g}}$ & $10^{-7}$ & $10^{-6}$ & $10^{-5}$ & $10^{-4}$ & $10^{-3}$ & $10^{-2}$ & $10^{-1}$ & 1 & 10 \\
\hline & G6: S-S/IVOC $\mathrm{i}_{\mathrm{i}, \mathrm{p}, \mathrm{p}+\mathrm{g}}$ & $10^{-8}$ & $10^{-7}$ & $10^{-6}$ & $10^{-5}$ & $10^{-4}$ & $10^{-3}$ & $10^{-2}$ & $10^{-1}$ & 1 \\
\hline
\end{tabular}

and NT-S-SVOC $g$ from the different precursors and generations of oxidation at 2 p.m. Also shown are the primary NT-POA and NT-P-S/IVOC ${ }_{g}$ emitted at 2 p.m. Figures SI- $8 \mathrm{a}$ and SI- $8 \mathrm{~b}$ show that five generations of oxidation make a significant contribution to NT-SOA with a peak for the 2nd generation (Fig. SI-8a), while four generations contribute to NT-S-SVOC $g$ with a peak for the first generation (Fig. SI-8b). Figures SI- $8 \mathrm{c}$ and SI-8d show that NTSOA is mostly composed of material with $c *$ between $1-$ $100 \mu \mathrm{g} \mathrm{m}^{-3}$ (Fig. SI-8c), and NT-S-SVOC $g$ is dominated by the higher volatility species with a $c *$ between 100 $10000 \mu \mathrm{g} \mathrm{m}^{-3}$ (Fig. SI-8d), as expected from partitioning theory on $c_{\mathrm{OA}} \sim 25 \mu \mathrm{g} \mathrm{m}^{-3}$. Finally, Figs. SI-8e and SI-8f show that NT-SOA is formed from bins 4-9 of the initially lumped primary emitted species (with the maximum in bin 6, the most volatile NT-P-SVOC $g$ class). The primary material in bins $1-3$ is almost exclusively in the particle-phase under the conditions of our study and thus it never has a chance to produce SOA by gas-phase oxidation. The NT-S-SVOC ${ }_{g}$ in the gas-phase at 2 p.m. originated from bins 5-9 (dominated by the initial IVOC), with the maximum for bin 9 , the NT-P-IVOC $g$ with the highest volatility (Fig. SI-8f).

\subsection{Total model SOA}

The total model SOA for our base case is shown in Fig. 7, as the sum of BG-SOA, UT-SOA, G-SOA, and NT-SOA. When combining the 3 models the total model SOA is close to the measurements throughout the simulation period, and the agreement is good given the combined measurement and 
model uncertainties. Thus the combination of 3 recent developments in SOA modeling shows promise for closing the gap between SOA measurements and models. However the prediction of a similar amount of SOA is not a stringent test and it does not mean that this combination of models is accurately capturing the mechanisms actually operating in the atmosphere. Additional insight on the appropriateness of the model combination used here can be gained by comparing intensive properties of the model vs. measured SOA, such as volatility, $\mathrm{O} / \mathrm{C}$ ratio, and ${ }^{14} \mathrm{C}$. Figure $7 \mathrm{~b}$ shows that the total model gas-phase SVOC have a mass about double the total model SOA, the overwhelming majority of which arises from the NT-SOA model and which carries high potential for additional SOA formation upon further aging.

The modeling of six other days of MCMA-2003 with the base case model results in similar agreement with measurements as for 9 April 2003. These comparisons are shown in Figs. SI-9 and SI-10 (note that G-SOA and G-SVOC $g$ are not included). For those days, there is a significantly higher OOA background and more meteorological variability, and the PBL breaks much earlier and more strongly than on 9 April 2003. Thus for 10 and 13 April 2003 we show the model results only until 11 and 10 a.m., respectively. The inclusion of NT-SOA for those two days is still able to close the gap between model SOA and measured OOA that was apparent when only the T or UT models were used.

To facilitate the visualization of the results of the combined (UT, G, and NT) model, we grouped all model species into a volatility basis set for display purposes. Each species was lumped to a volatility bin by rounding the logarithm of its saturation concentration $(\log c *)$ at $300 \mathrm{~K}$. The concentrations of model species at four different times ( 6 a.m., 9 a.m., 12 p.m., and 2 p.m.) are shown in Fig. 8. The early morning period is characterized by strong emissions and very low $\mathrm{OH}^{-}$concentrations, thus the majority of gas and particle organics at this time are freshly emitted from primary sources. At 9 a.m. the fresh emissions are still strong and photochemistry has started, as visible in Fig. 8b from the growth of secondary gas- and particle-phase species in all models. By noon (Fig. 8c) the traffic emissions are reduced and photochemistry is strong; there is a large growth of all gas- and particle-phase secondary species whose average volatility is starting to decrease which can be seen as a shift of mass bins to the left in the figure. Finally, at 2 p.m. photochemistry has been intense for several hours and additional emissions make a small contribution as they are diluted in the deep boundary layer at this time. The mass distribution of gas and particle products in Fig. 8d reflects a dominantly aged/secondary composition, and almost all of the SOA mass is composed of species with $c^{*} \leq 100 \mu \mathrm{g} \mathrm{m}^{-3}$, as expected. Gas-phase secondary SVOC have a larger concentration than SOA species, and carry an additional SOA forming potential as aging continues. The largest organic mass of any model species is in UT-pVOC.
An interesting feature of the NT model is clear from Fig. 8: since the oxidation of each species reduces its volatility by one order-of-magnitude (i.e. one $c *$ bin), these species "hit a wall" and cannot reduce their volatility significantly beyond the bin for which $c^{*} \sim 0.1 \times c_{\mathrm{OA}}$, since almost all of the species are in the particle-phase at that point and cannot undergo further gas-phase oxidation. Thus with the Robinson et al. (2007) formulation, this model cannot form significant mass of species with $c^{*} \ll c_{\mathrm{OA}}$.

\subsection{Characterization of base-case model SOA}

In order to further constrain the comparison of modeled and measured SOA, the volatility and atomic $\mathrm{O} / \mathrm{C}$ ratio are calculated for the model SOA and compared with observations. In addition, the trends for evolution of the model SOA at longer timescales than those studied here are characterized in two simple ways: evaporation upon isothermal dilution and aging without dilution.

\subsubsection{Evaporation of SOA upon Heating}

The evaporation of ambient OOA upon heating has been recently characterized in the field for the first time by using a thermodenuder-AMS combination (Huffman et al., 2008, 2009a), where it was found that HOA has higher volatility than OOA in Mexico City, contrary to most model representations which consider the POA as completely non-volatile, and consistent with the NT model of Robinson et al. (2007). A thermodenuder (TD) is a heated flowtube providing a certain residence time at elevated temperature, followed by a charcoal adsorption stage to limit recondensation of the evaporated gases on the particles. Since the evaporation upon heating can be readily calculated for model-produced SOA, the availability of these experimental data allows a new type of comparison of the intensive properties of model and measured SOA.

The volatility of UT and NT model SOA and gas SVOC mass at 2 p.m. was analyzed here in two ways. First an equilibrium calculation was performed using Eqs. (1) and (3) above. This calculation is simpler but it likely overestimates the evaporation of the model SOA as it ignores kinetic limitations to the evaporation (An et al., 2007; Faulhaber et al., 2009). However, it is useful to show the equilibrium calculation due to at least two reasons: (a) because this is the best estimate of the evaporation of the SOA under real atmospheric conditions where longer time scales apply and equilibrium is expected to be reached and (b) to serve as a comparison point for the kinetic calculations, to allow the reader to evaluate how far the TD is from equilibrium and what the evaporation would potentially be on a TD of long residence time and low particle losses. Thus, we are including the results of equilibrium calculation in this paper. Second, a kinetic evaporation model, based on that developed in Cappa et al. $(2007,2008)$ and consistent with the results of Faulhaber et al. (2009), was 

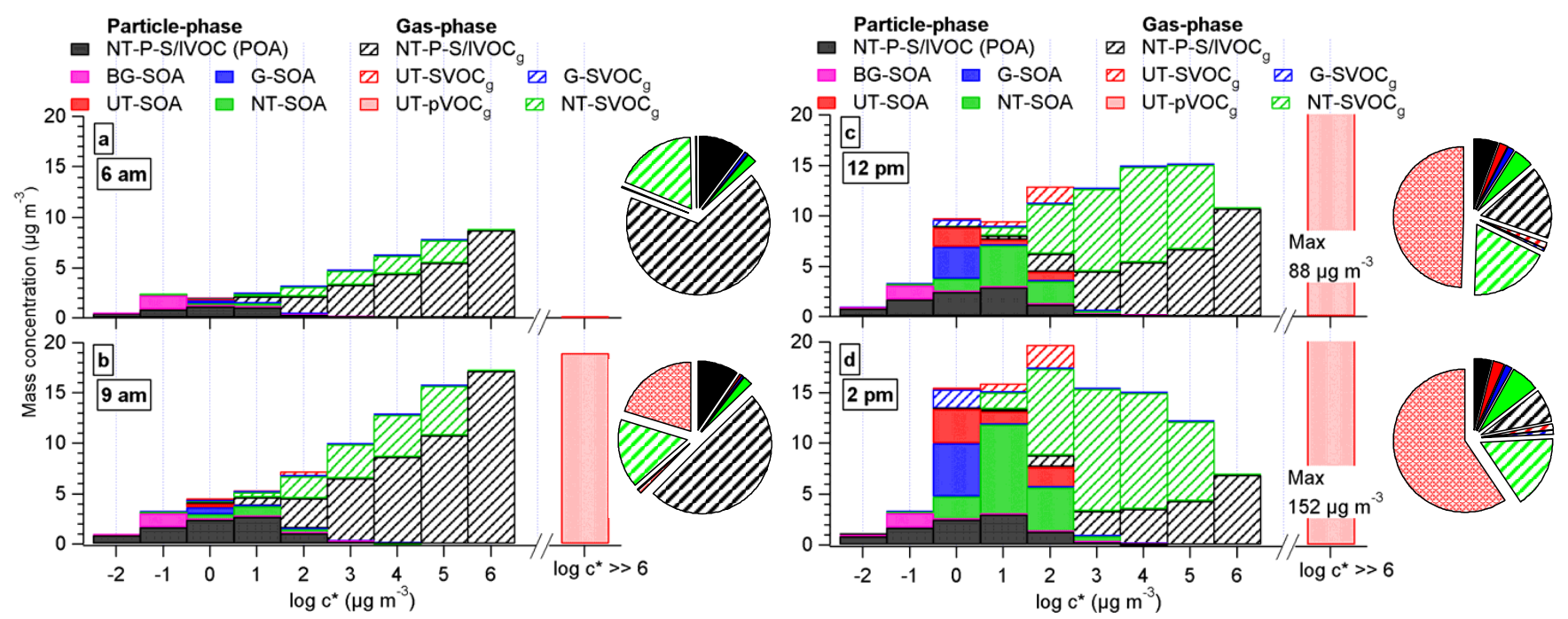

Fig. 8. Volatility basis set representation of all model primary and secondary species at four times during the case study. See text for details.
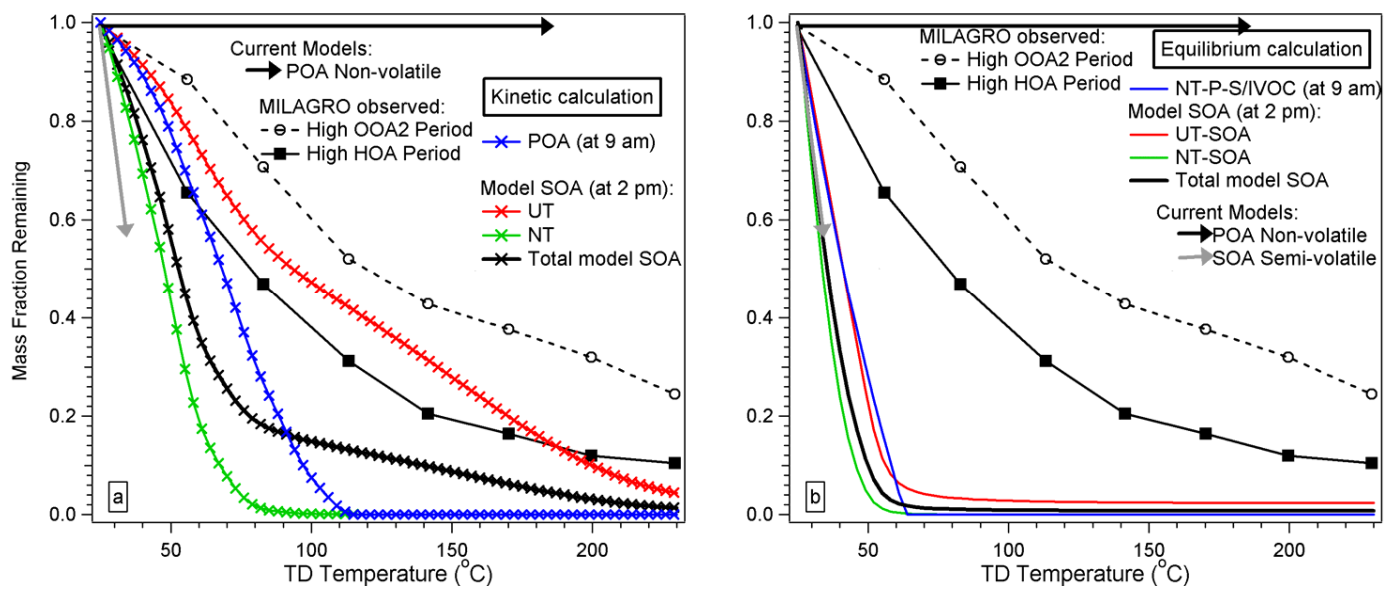

Fig. 9. Comparison of measured thermal denuder relative evaporation profiles during periods of high HOA and OOA contributions during MILAGRO 2006 (T0 supersite inside the city, data adapted from Huffman et al., 2009a) to the volatility of each model SOA as well as total model SOA. Panel (a) shows the results of the kinetic calculation while panel (b) shows the results of the equilibrium calculation. We do not calculate the evaporation of G-SOA due to large uncertainties associated with the relevant parameters (see text).

implemented with the parameters of the TD used here, an average mass-weighed particle size of $300 \mathrm{~nm}$ (Salcedo et al., 2006), an evaporation coefficient of 1 , and a diffusion coefficient in air of $5 \times 10^{-6} \mathrm{~m}^{2} \mathrm{~s}^{-1}$. The kinetic evaporation model was run for the temperature-dependent particle residence time in the TD (with a plug flow residence time - as defined by Huffman et al., 2008 - of $15 \mathrm{~s}$ at ambient temperature, which matches the TD used during MILAGRO, unless stated otherwise). The kinetic model is capable of reproducing measured TD curves for single component aerosols where the vapor pressure and $\Delta H_{\text {vap }}$ are known. The temperature range considered for the equilibrium model was -100 to $+300^{\circ} \mathrm{C}$, a range that brackets the temperatures from the coldest in the troposphere to the hottest achievable in our TD.
Gas- and particle-phase glyoxal is not included in the model TD analyses as the uptake and accretion reactions of G-SOA in the water phase are not well understood and it is not clear how they would evolve as temperature changes. For the same reason, we do not include glyoxal in the analysis below of model SOA behavior upon dilution (Sect. 4.5.3). Likewise, BG-SOA is not included in TD analysis as it is not clear how to estimate the gas-phase SVOC associated with BG-SOA.

Figure 9 shows the results of the kinetic and equilibrium evaporation models for the secondary species from only the UT and NT models, together with the experimentally observed TD evaporation of total OA during periods dominated by HOA or fresh SOA (OOA-2) (Huffman et al., 2009a) during the MILAGRO 2006 field campaign. Also shown is the 

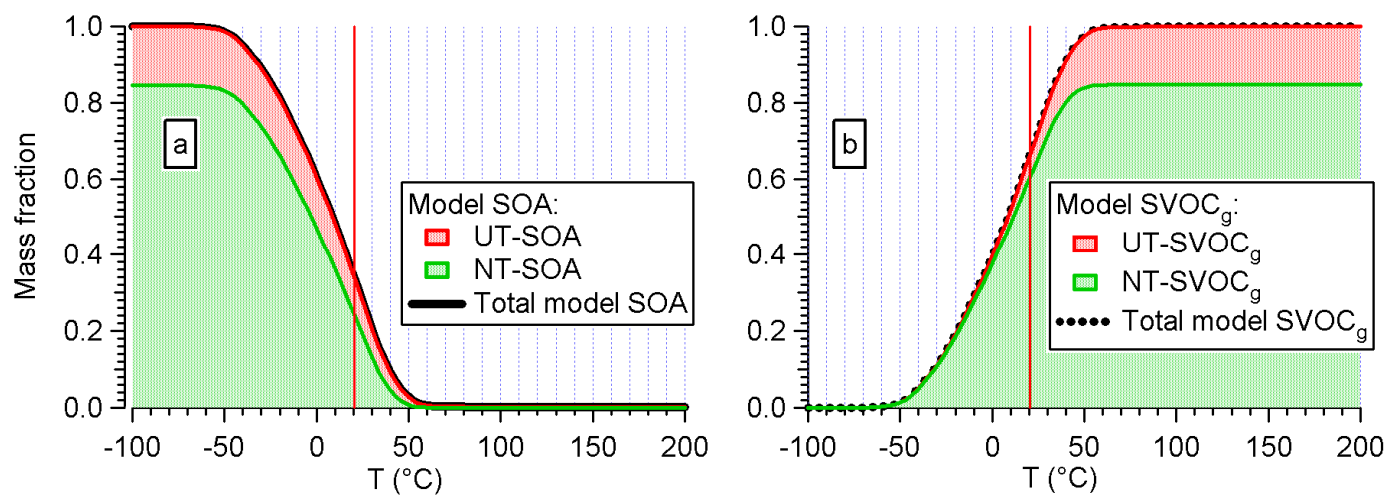

Fig. 10. Temperature dependence under equilibrium of UT-SVOC $g+p$ and NT-S-SVOC $g+p$ for model results at 2 p.m. in our case study. Mass loadings are normalized to the sum of total UT and NT models mass loadings at 2 p.m. We do not calculate evaporation of G-SOA due to the large uncertainties associated with the relevant parameters (see text).

volatility of primary NT model mass at 9 a.m. (peak of primary emissions). All the data is plotted as fraction of OA lost due to heating from ambient temperature. Figure $9 \mathrm{~b}$ shows that all model OA species are very volatile under equilibrium. For the kinetic calculation the modeled evaporation of total SOA is larger than that measured in MILAGRO during periods of high OOA contribution. The total model volatility is dominated by that from the high volatility of the NTSOA since most of the model SOA arises from that mechanism, while the calculated evaporation of the UT-SOA model is closer to the observations. The evaporation of the model POA and P-S/IVOC from the NT model is similar to that observed (during high HOA periods) until $\sim 75^{\circ} \mathrm{C}$ but much larger at higher temperatures.

Figure 10 shows the results of the equilibrium model for the secondary species from the UT and NT models over a wider temperature range which also includes cooling. At ambient temperature $\sim 34 \%$ of the total available SVOC mass is present as SOA, which condenses completely (and thus almost triples the SOA mass) upon cooling to $-50^{\circ} \mathrm{C}$ (as in lofting to the upper troposphere). The model SOA is very volatile and more than half of it evaporates upon heating to $40^{\circ} \mathrm{C}$, with little being left after $60^{\circ} \mathrm{C}$. The evolution of the speciation of both models upon heating or cooling (under equilibrium) is shown in Fig. SI-11 (http://www.atmos-chem-phys.net/9/5681/2009/ acp-9-5681-2009-supplement.pdf). Figure 10 also shows that model SOA increases significantly upon cooling, and future research is needed in order to characterize the SOA partitioning at low temperatures. An experiment in which semivolatiles were captured at several temperatures lower than ambient and then chemically analyzed (or more practically, captured at a very low temperature and desorbed with a slow temperature ramp on the collection surface similar to the TDPBMS instrument of Paul Ziemann, see e.g. Tobias and Ziemann, 1999, 2000) could in principle provide information that would be of great value for constraining SOA models such as those used in this paper.
It is possible in principle that HOA and/or OOA in mixed ambient particles have an evaporation coefficient much lower than 1. If that was the case, it could explain some of the kinetic model/measurement differences observed here. The evaporation coefficients of various organic species in singlecomponent aerosols and simple mixtures reported in the literature are near 1 (Pound, 1972; Cammenga, 1980; Davis et al., 1980). However, recent work suggests that the evaporation coefficients may be lower than one for more complex organic aerosol mixtures, such as those produced in chamber studies of SOA formation, although the evidence is far from conclusive (Stanier et al., 2007; Grieshop et al., 2007, $2009 \mathrm{c})$. In order to test the dependence of model mass evaporation to the changes in evaporation coefficients, we repeated the kinetic calculation shown in Fig. 9a while changing the evaporation coefficient to $0.1,0.01$ and 0.001 . The results are shown in Fig. SI-12 and confirm that decreasing the evaporation coefficients to values smaller than 1 drastically reduces the evaporation of model mass in the simulated TD. For example, an evaporation coefficient of 0.1 makes the agreement between the volatility of model NT-POA and HOA measured during MILAGRO somewhat better (Fig. SI-12a). Likewise, lowering the evaporation coefficient reduces the disagreement between the modeled and measured SOA evaporation (Fig. SI-12b). However, low evaporation coefficients result in calculated curves for the UT-SOA model which diverge greatly from TD measurements of SOA formed in chamber experiments (e.g. Fig. 4e in Huffman et al., 2009b), casting doubt on the likelihood of evaporation coefficients much below unity. Further research to constrain the evaporation coefficients of real POA and SOA in the laboratory and the field should be a high priority of the OA community.

The UT model secondary species have significantly lower $\Delta H_{\text {vap }}\left(36 \mathrm{~kJ} \mathrm{~mol}^{-1}\right)$ than the species in the NT model (range from $70-148 \mathrm{~kJ} \mathrm{~mol}^{-1}$ ), and as a result the UT-SOA species vapor pressures increase much more slowly with temperature. To test whether the difference in the calculated evaporation of UT vs NT SOA is due mainly to differences in 


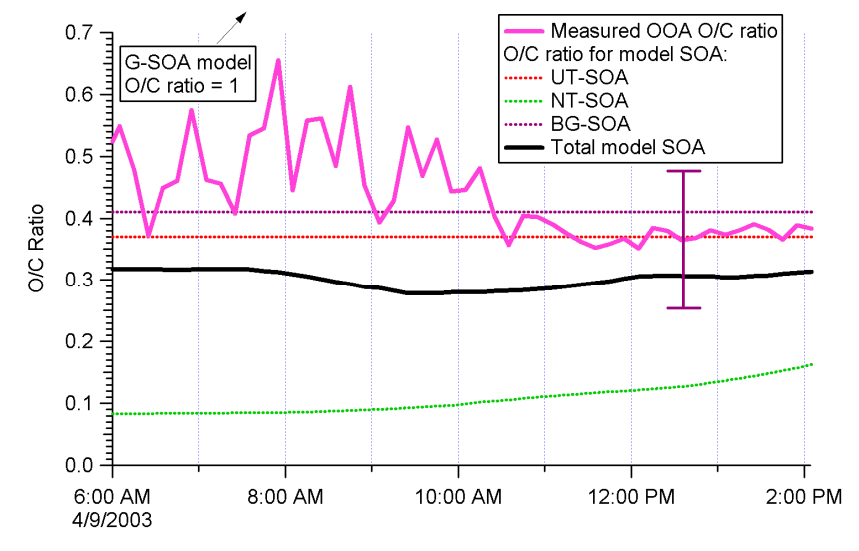

Fig. 11. Atomic O/C ratios for total OOA (estimated from the measurements) and for model SOA species. The error bar shows the estimated uncertainty of measured OOA O/C ratio of $\pm 30 \%$ (Aiken et al., 2007, 2008).

$\Delta H_{\text {vap }}$, we repeated the kinetic TD simulation in 2 ways: first we changed $\Delta H_{\text {vap }}$ for all UT model species to $100 \mathrm{~kJ} \mathrm{~mol}^{-1}$ while keeping the NT-SOA $\Delta H_{\text {vap }}$ as in Fig. 9, and second we changed $\Delta H_{\text {vap }}$ for all NT-SOA species to $36 \mathrm{~kJ} \mathrm{~mol}^{-1}$ while keeping UT-SOA $\Delta H_{\text {vap }}$ as in Fig. 9. The results of these two kinetic TD simulations are shown in Fig. SI-13 and show that indeed most of the differences between the thermograms of both models are eliminated when the same $\Delta H_{\text {vap }}$ is used.

In order to test the effect of residence time on the kinetic calculation (An et al., 2007), we repeated the calculation for two additional residence times, $t_{\text {res }}=3 \mathrm{~s}$ and $t_{\text {res }}=22 \mathrm{~s}$, and the results are shown in Fig. SI-14. For very short $t_{\text {res }}=3 \mathrm{~s}$ there is a significant reduction of the fraction of SOA evaporated, while for the longer $t_{\text {res }}=22 \mathrm{~s}$ the evaporation is closer to the evaporation in the actual residence time, since both models are already close to equilibrium in either case. This confirms that TD residence time is a very important parameter, especially for residence times of the order of a few seconds. Note that the thermal entrance length needs to be taken into account for short experimental residence times as pointed out by Fierz et al. (2007), which may explain some of the very low evaporation cases reported by An et al. (2007).

Finally, we tested the dependence of kinetic evaporation model to the changes in particle size, and compare it to the base-case calculations that use an average mass-weighed particle size of $300 \mathrm{~nm}$ (Salcedo et al., 2006). The results of changing the particle size for $\pm 200 \mathrm{~nm}$ (with an evaporation coefficient of 1) is shown in Fig. SI-15. As expected decreasing the particle size to $100 \mathrm{~nm}$ increases the evaporation of model mass, while increasing the particle size to $500 \mathrm{~nm}$ decreases it. This is consistent with the expected behavior of model fractional evaporation upon changes in particle size.

As described above, there is a significant difference in the description of the TD results depending on the assumption of equilibrium or of kinetic limitations to the evaporation. This is an important issue, as there can be a large difference in species evaporation especially for short residence times. Increasing residence time in a TD allows evaporation closer to that under equilibrium, but however it can also exacerbate particle losses in the denuder, especially for the smaller particles that result from evaporation and which have much higher diffusion coefficients than the original particles (Huffman et al., 2008). There are also significant uncertainties in e.g. evaporation coefficients and enthalpies of vaporization which have an important influence in the evaporation, as discussed above, and exploring these issues in more detail is beyond the scope of this paper. Based on the calculations presented here, we recommend that the TD measurements use a plug flow particle residence time at ambient temperature (PFRT, Huffman et al., 2008) between 10-15 s to avoid the most severe kinetic limitations to evaporation.

\subsection{2 $\mathrm{O} / \mathrm{C}$ ratio}

Recently a method to estimate the atomic $\mathrm{O} / \mathrm{C}$ ratio for bulk $\mathrm{OA}$ and OA components from AMS mass spectra has been developed (Zhang et al., 2005b; Aiken et al., 2007, 2008). $\mathrm{O} / \mathrm{C}$ is observed to be low $(\sim 0.05)$ for vehicle emissions and increase from $\sim 0.4$ for fresh SOA to values approaching 1 for aged SOA (Aiken et al., 2008; Mohr et al., 2009; Shilling et al., 2009). This allows the comparison of another intensive property of the SOA between models and observations. We have estimated the $\mathrm{O} / \mathrm{C}$ of the ambient OOA during our case study based on the ratio of $m / z 44$ to total OOA, using an empirical approximation that was derived from Mexico City OA data (Aiken et al., 2008). The estimated O/C for the OOA measurements and the model $\mathrm{O} / \mathrm{C}$ are compared in Fig. 11. The OOA has an average $\mathrm{O} / \mathrm{C}$ ratio of $\sim 0.45$ for the early hours of the photochemistry due to the presence of a more aged OOA background, and is very noisy as smaller amounts of material are present, and it is reduced with the addition of fresher SOA to an average OOA O/C of $\sim 0.38$ by 2 p.m. Based on the results of Aiken et al. (2007, 2008), the uncertainty of measured $\mathrm{OOA} \mathrm{O} / \mathrm{C}$ ratio is estimated to be $\pm 30 \%$. The uncertainty of the model SOA O/C ratio is difficult to estimate but it is likely at least as large as for the measured OOA.

The predicted $\mathrm{O} / \mathrm{C}$ ratios are very different for the different models. We estimate the $\mathrm{O} / \mathrm{C}$ for UT-SOA as $\sim 0.37$ based on chamber experiments with aromatic precursors (Aiken et al., 2008), which is very similar to the observed OOA O/C ratio. The O/C for the G-SOA model is uncertain as the detailed composition of this SOA has not been characterized, and it can be different depending on the type of oligomerization reactions that may take place. The $\mathrm{O} / \mathrm{C}$ ratio for the di-hydrated glyoxal monomer is $\mathrm{O} / \mathrm{C}=2$, and this ratio approaches $\mathrm{O} / \mathrm{C}=1$ for longer chain oligomers (Volkamer et al., 2009). Due to lack of additional information, here we estimate an $\mathrm{O} / \mathrm{C}$ ratio of 1 (same as glyoxal), which is higher than any other model 

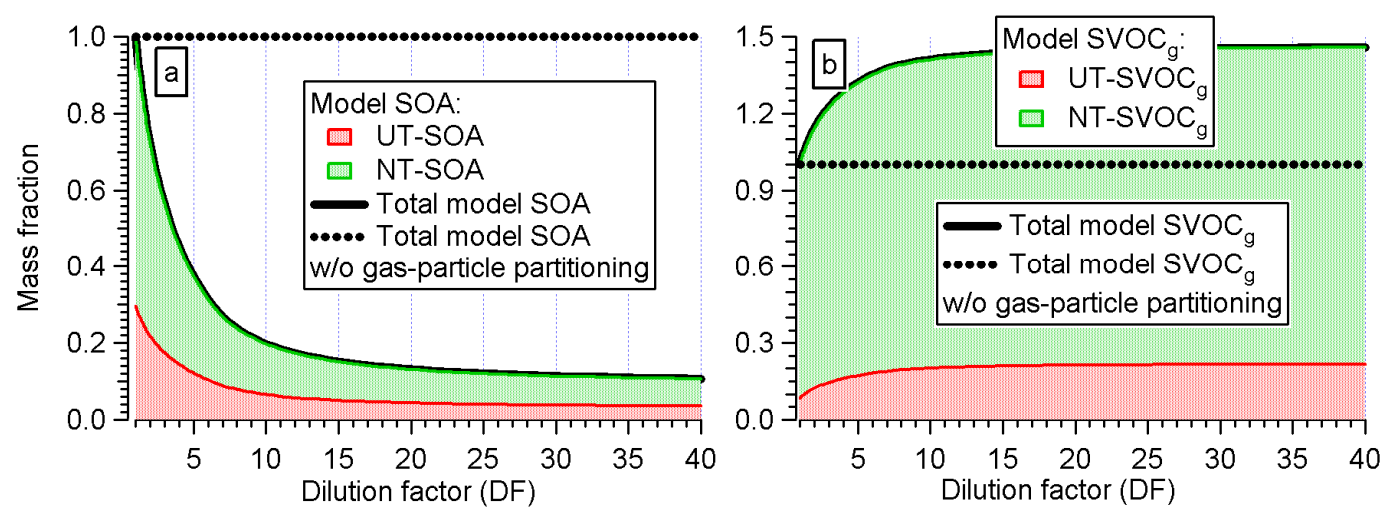

Fig. 12. Evolution with dilution of total model SOA at 2 p.m. during our case study. The results are shown by plotting the mass fractions in the particle and gas-phase, relative to the mass in that phase before dilution. We do not calculate the evaporation of G-SOA due to large uncertainties associated with the relevant parameters (see text). The dilution air is assumed to have a background SOA concentration of $0.2 \mu \mathrm{g} \mathrm{m}^{-3}$ (see Figs. SI-18 and 19 (http://www.atmos-chem-phys.net/9/5681/2009/acp-9-5681-2009-supplement.pdf) for sensitivity studies of that assumption).

SOA O/C ratio. The assumed G-SOA O/C ratios are higher than those measured for bulk fresh SOA and more similar to those observed in aged ambient aerosol, but they are compatible with G-SOA making a non-dominant contribution to ambient SOA mass (of the order of that estimated here and by Volkamer et al., 2007a) that nonetheless increases the average $\mathrm{O} / \mathrm{C}$ ratio of the predicted SOA. Finally, we estimate the $\mathrm{O} / \mathrm{C}$ ratio of BG-SOA to be the average observed $\mathrm{O} / \mathrm{C}$ between midnight and 7 a.m. of 0.41 .

The O/C ratio for NT-SOA is calculated for the total SOA produced in this model, as each generation of oxidation products adds $7.5 \%$ to the mass due to the addition of oxygen $(\sim 1 \mathrm{O}$ atom per oxidation). The O/C for NTSOA gradually increases during the day as photochemistry is producing more oxidized material from a value of 0.08 at 6 a.m. to reach a maximum of $\sim 0.16$ at 2 p.m. These values are significantly below the $\mathrm{O} / \mathrm{C}$ estimated from the measurements. The evolution of NT-SOA O/C ratio in different volatility bins at four times during the case study is shown in Fig. SI-16 (http://www.atmos-chem-phys.net/9/ 5681/2009/acp-9-5681-2009-supplement.pdf). The increase of NT-SOA O/C ratio in the afternoon is mainly due to the species with $c *$ between $1-100 \mu \mathrm{g} \mathrm{m}^{-3}$, as those species have gone through several generations of oxidation by 2 p.m. Finally, the average model SOA O/C ratio is $\sim 0.3$, which is $\sim 0.1$ below the observations, indicating that this combination of models produces SOA which is somewhat less oxygenated than the OOA measured $\mathrm{O} / \mathrm{C}$ ratio. The OOA O/C ratios measured at the T0 ground site during MILAGRO2006 (Aiken et al., 2008) range from 0.52 for OOA-2 to 0.83 for OOA-1, which are significantly higher than during our case study, likely due to the presence of more aged SOA during the average conditions of MILAGRO.

\subsubsection{Evaporation of model SOA upon dilution}

The gas-particle distribution of a SVOC depends strongly on the amount of OA available for partitioning (Eq. 1). Grieshop et al. (2007) varied dilution in chamber studies of SOA formed in $\alpha$-pinene ozonolysis, and found that dilution caused evaporation of SOA consistent with partitioning theory over a time scale of several hours. As the SOA produced in Mexico City is advected over regional scales, it will also be diluted, which will reduce the OA concentration and lead to some evaporation of SVOC back to the gas-phase. Cooling upon ascent of the airmass, and additional SOA production and SOA volatility reduction upon additional oxidation will counteract this effect. A coupled simulation of the evolution of SOA including all effects is beyond the scope of this paper. Here we perform two simple studies of evaporation upon dilution (this section) and aging without dilution (next section) to establish some qualitative bounds on the SOA evolution.

The effect of isothermal dilution when applied to the model results at 2 p.m. is shown in Fig. 12. To present the effects of dilution in an easily understandable manner, we multiply the concentration after dilution (and potential evaporation) by the dilution factor. This transformation will result in a constant value for non-volatile species or gas-phase species not involved in partitioning (e.g. CO). This will not be the case for a semivolatile compound, for which the adjusted final concentration will be smaller than the initial concentration. Values are normalized to the total SOA and gas SVOC mass at 2 p.m., respectively.

Figure 12a shows that the sum of UT-SOA and NT-SOA evaporates strongly upon moderate dilution: $\sim 1 / 3$ of the SOA evaporates upon dilution by a factor of 3 , and more than $3 / 4$ after dilution by a factor of 10 . Unlike in the case of evaporation upon heating, here the UT-SOA and NT-SOA show similar volatility since their vapor pressure distributions are 

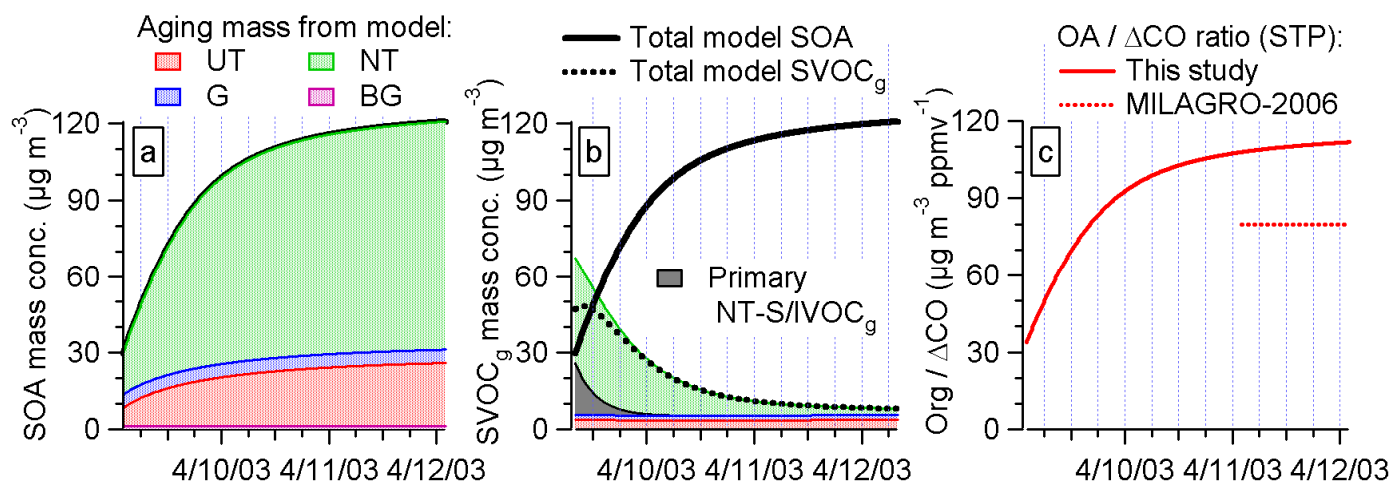

Fig. 13. Evolution of model SOA upon further photochemical aging without dilution, starting with the simulated SOA at 2 p.m. in our case study, and with a constant $\mathrm{OH}^{-}$concentration of $1.46 \times 10^{6} \mathrm{~cm}^{-3}$. Panels (a) and (b) show the evolution of model SOA and gas-phase SVOC. Panel (c) shows the predicted total OA/ $\triangle \mathrm{CO}$ ratio under STP conditions (1 atm and $273.15 \mathrm{~K}$ ) to facilitate comparison with other studies.

more similar (Fig. 8) and the large differences in $\Delta H_{\text {vap }}$ discussed above do not play a role under our isothermal assumption. The speciation of the changes of SOA and gas SVOC upon dilution is shown in Fig. SI-17. The lumped SOA compounds in both models evaporate according to their vapor pressures, leaving behind only small amounts of nominally non-volatile SOA products (from aromatic oxidation in the low- $\mathrm{NO}_{\mathrm{x}}$ regime).

A ground-based study during MILAGRO 2006 reported that $\sim 25 \%$ of the SOA formed at the surface may evaporate due to dilution in the afternoons (Hennigan et al., 2008). This strong evaporation of SOA upon dilution is not apparent in the MILAGRO 2006 aircraft observations, where SOA (when normalized to $\mathrm{CO}$ ) continues to increase as pollution leaves the Mexico City basin and is being diluted during low BB periods (Kleinman et al., 2008; DeCarlo et al., 2008). In order to explain the more constant $\mathrm{SOA} / \triangle \mathrm{CO}$ ratios observed during dilution into regional air in MILAGRO and other field studies (e.g., de Gouw et al., 2005), either the volatility of real SOA upon dilution is lower than the models predict, or additional SOA formation or volatility reduction upon aging compensates for the evaporation. Given the direction of the discrepancies in the model vs. measurement thermal denuder curves above, it is likely that atmospheric SOA is less volatile than the model predictions. A small positive bias in the evaporation when comparing with aircraft observations may be due to the fact that we modeled the evaporation of model SOA under dilution at the constant temperature of $2 \mathrm{p} . \mathrm{m} .\left(21^{\circ} \mathrm{C}\right)$. The real ambient dilution of the Mexico City pollution plume is not isothermal, and the temperatures of pollution plumes in regional air at the same altitude are $\sim 5^{\circ} \mathrm{C}$ cooler than over the city (DeCarlo et al., 2008). However Fig. 9 shows that the reduction in evaporation due to this effect is insufficient to compensate for the stronger evaporation brought about by dilution of $\sim 6 \%$ per hour quantified from the aircraft measurements (Zaveri et al., 2007), corresponding to a factor of 2 every $12 \mathrm{~h}$.
Finally, in the dilution base-case of the model SOA presented here, all model species are being diluted with air that contains an assumed OA background of $0.2 \mu \mathrm{g} \mathrm{m}^{-3}$, based on typical levels observed in clean regional air by DeCarlo et al. (2008). To highlight the importance of background SOA levels (Shrivastava et al., 2006), we repeated the model dilution simulation shown in Fig. 12 for two cases: first, by assuming that no OA background is present (Fig. SI-18, http://www.atmos-chem-phys.net/9/5681/2009/ acp-9-5681-2009-supplement.pdf), and second, by assuming a $1 \mu \mathrm{g} \mathrm{m}^{-3}$ background (Fig. SI-19). This quantity significantly modulates the strong evaporation of SOA upon dilution, especially at high dilution factors: at $\mathrm{DF}=40,28 \%$, $11 \%$, and $3 \%$ of the total model SOA stays in the particlephase for the 3 decreasing background OA levels. At $D F=10$, $36 \%, 20 \%$, and $17 \%$ of the model SOA remain at the different background levels.

\subsubsection{Additional SOA formation after further aging of the airmass}

The model SOA and especially the gas SVOC has potential for aging while pollution leaves the city and is being further oxidized and processed. We have carried out a 3-day aging experiment of the model SOA and gas-phase SVOC mass to evaluate the potential for additional SOA formation at longer timescales. Conceptually an air parcel with the concentrations existing at 2 p.m. is advected outside of the city, so that no additional emissions are added, and no loss processes (dry deposition, etc.) are in effect. Any VOC remaining in the parcel are allowed to oxidize, and the model is run at constant temperature for 3 days. The oxidation was calculated with constant values of $\mathrm{OH}^{-}=1.46 \times 10^{6}$ molec $\mathrm{cm}^{-3}$ (24-hr average for polluted outflow during MILAGRO, C. Cantrell, NCAR-ACD, personal communication, 2008) and $\mathrm{O}_{3}=60 \mathrm{ppbv}$. The result of this simple aging test is given in Fig. 13, showing that UT-SOA and NT-SOA grow $\times 3.6$ and $\times 5.6$, respectively, after 3 days 
of aging showing that there is a large additional SOA formation potential for both models. $\mathrm{NO}$ and $\mathrm{HO}_{2}$ concentrations were taken to be equal to those at 2 p.m. during 9 April. This may bias our simulation against the low- $\mathrm{NO}_{\mathrm{x}}$ products of aromatics, which would result in even more UT-SOA formation upon aging than simulated here. The speciation of both models during the 3 days of aging is given in Fig. SI-20.

The total model SOA O/C ratio after 3-days of aging is $\sim 0.34$. OOA O/C ratios observed for aircraft measurements during MILAGRO-2006 range from 0.64 for OOA-2 to 1.02 for OOA-1 (Aiken et al., 2008; DeCarlo et al., 2008) indicating that aged OOA has much higher oxygen content than our model SOA. Also shown in the right-most panel of Fig. 13 is the $\mathrm{OA} / \triangle \mathrm{CO}$ ratio (subtracting $100 \mathrm{ppb}$ from $\mathrm{CO}$ to account for the typical background (DeCarlo et al., 2008; Herndon et al., 2008; Kleinman et al., 2008)) which for STP conditions starts at $\sim 35 \mu \mathrm{g} \mathrm{sm}^{-3} \mathrm{ppmv}^{-1}$ at the beginning of aging, and ends $\sim 109 \mu \mathrm{g} \mathrm{sm}^{-3} \mathrm{ppmv}^{-1}$ after three days of aging. DeCarlo et al. (2008) and Kleinman et al. (2008) recently reported $\mathrm{OA} / \triangle \mathrm{CO}$ ratio for aircraft measurements during MILAGRO. OA/ $\triangle \mathrm{CO}$ ratios for the measurements taken just above MCMA city basin during periods of low $\mathrm{BB}$ are approximately $40 \mu \mathrm{g} \mathrm{sm}^{-3} \mathrm{ppmv}^{-1}$; OA/ $\Delta \mathrm{CO}$ ratios for the measurements of more aged air masses are approx. in the range of $70-90 \mu \mathrm{g} \mathrm{sm}^{-3} \mathrm{ppmv}^{-1}$. The model presented here overshoots the range of observed $\mathrm{OA} / \triangle \mathrm{CO}$ ratio increase during 3-day aging (even without including G-SOA in these aging simulations).

\section{Model sensitivity studies}

\subsection{Sensitivities to OA phase activity coefficients $(\zeta)$}

The partitioning base-case for model species was presented in Sect. 3.5 and Fig. 3, where model species partition to two OA phases, POA and SOA ("2OP”). Here we test the sensitivity of the model to this assumption. Figure 14 shows the schematic of the schemes tested: Fig. 14a shows a one OA phase ("1OP") case in which all model POA and SOA partition to a single organic phase, $\mathrm{POA}+\mathrm{SOA}$ phase, with $\zeta=1$ (except glyoxal which is treated as before). Figure $14 \mathrm{~b}$ shows a three OA phases ("3OP") case in which each type of POA and SOA partitions only in its own phase with $\zeta=1$ and to any other model OA with $\zeta=\infty$ (i.e. the SOA from each model does not partition to any other model formed OA). These are two limiting cases that allow evaluating the sensitivity of the model results to the most extreme assumptions. The 1OP assumption has been standard in SOA models to date (e.g. Chung and Seinfeld, 2002), but was not adopted as default here given the findings of Song et al. (2007) that indicate much reduced SOA partitioning in a POA phase.

Figure 15 compares the results of all cases. For these limiting partitioning cases the total model SOA mass shows very little change between the $1 \mathrm{OP}$ and $2 \mathrm{OP}$ cases, and $\sim 15 \%$ re- duction of total SOA for the 3OP case. Compared to the base-case, UT-SOA is more sensitive to the amount of OA it can partition to: in the 1 OP case UT-SOA increases by $6 \%$ at 2 p.m. and by a larger fraction earlier in the day when the HOA/OA fraction is higher, while in the 3OP case it decreases by $35 \%$ (Fig. 15b). This high sensitivity is not surprising since UT-SOA is a small fraction of the OA mass. The NT model (Fig. 15c) is not as sensitive to the OA mass available for partitioning, for three reasons. First, the NTSOA represents $58 \%$ of the average base-case model SOA, and thus is less sensitive to partitioning in the rest of the phases. Secondly, as the mass available for partitioning of $\mathrm{P}-\mathrm{S} / \mathrm{IVOC}$ increases, a smaller amount of these species is introduced into the model. Thirdly, this model has a "selfcompensating" behavior during oxidation: if the mass of OA available for partitioning decreases, more of the species are in the gas-phase where they are oxidized leading to lower volatility species and more SOA. Conversely if the partitioning mass increases, more of the species from this model are trapped in the particle phase more of the time, leading to a decreased oxidation rate. The relatively low sensitivity of SOA to the partitioning assumptions is partially due to the relatively high OA concentrations in this case study. If $c_{\mathrm{OA}}$ was below the $c^{*}$ of most condensable species in the air (SOA+gas SVOC), changes in the amount of $c_{\mathrm{OA}}$ would more dramatically change the amount of total model SOA (Chang and Pankow, 2008), as exemplified by the dilution cases described above.

\subsection{Sensitivities of NT-SOA model}

Due to the significance of the extra SOA introduced by the NT model, and the poor constraining of many parameters in the model, it is important to test the sensitivity of the NT model to key uncertain parameters. Here we evaluate two sensitivity cases: (a) the effect of the relative amount of IVOC mass introduced, and (b) the effect of a recent update of the NT model parameters by Grieshop et al. (2009a).

The NT model introduces new, previously uncounted for mass of IVOC species within a volatility range of $10^{4}-$ $10^{6} \mu \mathrm{g} \mathrm{m}^{-3}$ (Robinson et al., 2007). The amount of IVOC mass introduced is $1.5 \times \mathrm{SVOC}$ mass, but the authors report a range of uncertainty of the multiplying factor from 1 to 3 . We have evaluated these two limit cases here, as shown in Fig. 16. Decreasing the amount of IVOC to $1 \times$ SVOC decreases the total SOA mass slightly ( $4 \%$ on average over the simulation period; all later numbers are also averages) primarily due to the decrease of NT-SOA ( $8 \%$ ), but also due to the slight decreased partitioning of UT-SOA (2\%). Total model gas SVOC decreases more significantly (24\%), mainly due to the decrease from the NT model (27\%). Increasing the amount of IVOC to $3 \times$ SVOC mass increases the total SOA mass moderately $(17 \%)$ primarily due to the increase in NT-SOA (31\%), and to a small increase in UTSOA $(6 \%)$. There is a more drastic change in model gas 
“ONE OA PHASE” (“1OP”)

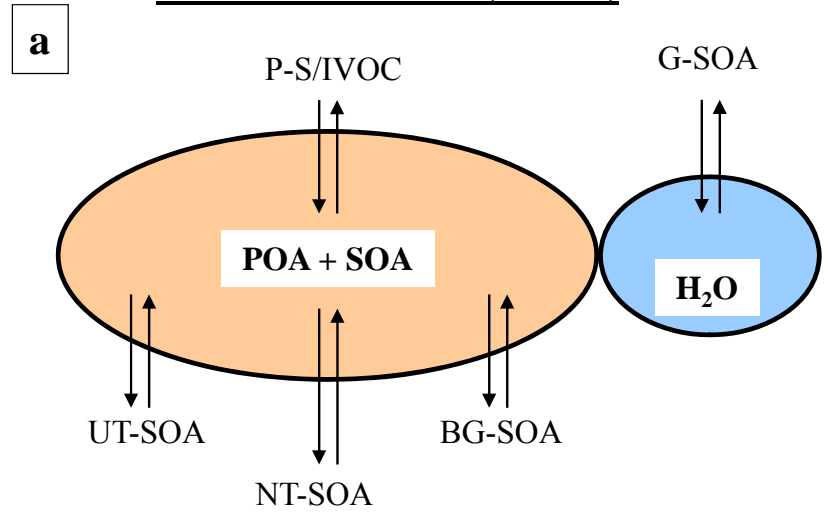

“THREE OA PHASES" (“3OP”)

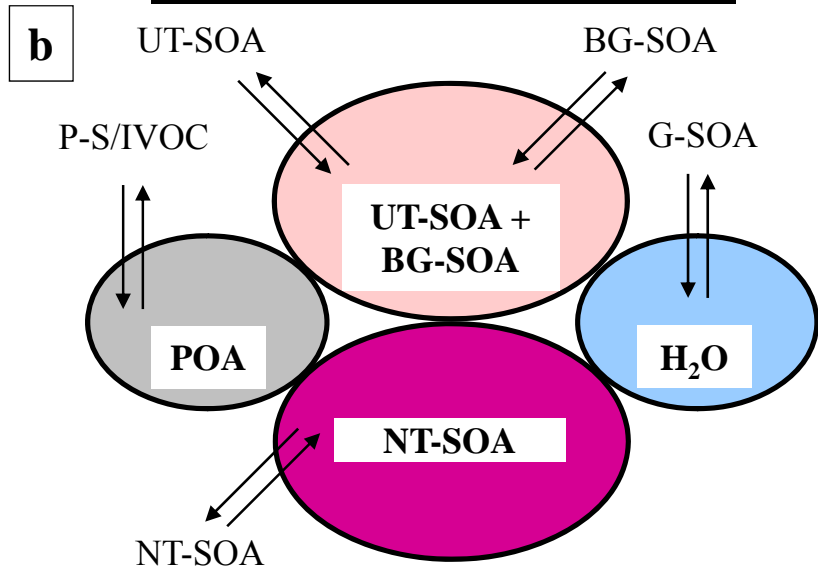

Fig. 14. Schematic of the two sensitivity cases for partitioning phase assumptions/activity coefficients. Panel (a) shows a "one OA phase" case in which all model POA and SOA partition to a single organic phase (POA + SOA phase) with $\zeta=1$ (except for glyoxal SOA that partitions to the water phase). To explore the sensitivity to more extreme assumptions, panel (b) shows a "three OA phases" case in which each type of POA and SOA partitions only in its own phase with $\zeta=1$ and to any other model OA with $\zeta=\infty$.

SVOC (increase of $71 \%$ ) mainly due to the strong increase of NT-SVOC $g$ (78\%), which is compensated by a slight decrease in UT-SVOC $g(8 \%)$ due to increased partitioning. The changes in IVOC/SVOC ratio thus affect local SOA production only slightly; however changes in this ratio will greatly affect regional SOA production (cf. "aging simulation" above) due to the very large pool of gas-phase species that is modified with those changes. We repeated the aging simulations for the IVOC to SVOC ratios 1 and 3. For the 3-day simulation, IVOC/SVOC $=1$ produces an $\mathrm{OA} / \Delta \mathrm{CO}$ ratio in the range of $32 \mu \mathrm{g} \mathrm{sm}^{-3} \mathrm{ppmv}^{-1}$ (at the start of simulation) to $93 \mu \mathrm{g} \mathrm{sm}^{-3} \mathrm{ppmv}^{-1}$ (at the end of the simulation). The same range of $\mathrm{OA} / \Delta \mathrm{CO}$ for $\mathrm{IVOC} / \mathrm{SVOC}=3$ is $41-167 \mu \mathrm{g} \mathrm{sm}^{-3} \mathrm{ppmv}^{-1}$. The later range of $\mathrm{OA} / \Delta \mathrm{CO}$ is too high when compared to the measurements during MILAGRO
(DeCarlo et al., 2008; Kleinman et al., 2008), suggesting that IVOC/SVOC ratios close to 1 produce concentrations more consistent with the regional observations. However the constraint in the actual amount of IVOC is weak, as similar SOA concentrations may be produced from a higher amount of IVOC if fragmentation reactions of alkoxy radicals are more important than assumed in this mechanism. The speciation of the UT and NT models for this sensitivity study is given in Fig. SI-21.

The mechanism of Robinson et al. (2007) has recently been updated to better match the evolution of chamber SOA from wood smoke, which has a similar distribution of semivolatile species as diesel emissions (Grieshop et al., 2009a). This updated NT model uses following new parameters: i) $k_{\mathrm{OH}}=2 \times 10^{-11} \mathrm{~cm}^{3} \mathrm{molec}^{-1} \mathrm{~s}^{-1}$; ii) the mass increase due to the oxygen addition per oxidation step is $40 \%$; iii) the range of $\Delta H_{\text {vap }}$ is $46-77 \mathrm{~kJ} \mathrm{~mol}^{-1}$; iv) every generation of oxidation decreases the $c^{*}$ of the products by 2 orders of magnitude ( 2 lumped bins) per oxidation step. The assumptions about the linking of the $c^{*}$ and $\Delta H_{\text {vap }}$ are the same as in the base case model. The results of simulations with these new parameters are given in Fig. SI-22 (http://www.atmos-chem-phys.net/9/5681/2009/ acp-9-5681-2009-supplement.pdf). The total amount of NTSOA grows $\sim 62 \%$ on average when compared to the base case simulation, and the mass of NT-S-SVOC ${ }_{g}$ decreases by $\sim 40 \%$, due to the larger decrease of volatility, higher oxygen gain per oxidation step of the gas-phase NT model species. This causes the model to slightly overpredict the observations. However, by 2 p.m. only three generations of oxidation of secondary material are formed (as opposed to five generations in the base case) due to the slower $\mathrm{OH}^{-}$reactivity of gaseous species. The intensive properties of NT SOA with the updated NT model shows that its volatility is somewhat smaller but still too high when compared to the observed SOA volatility (Fig. SI-23). Also, the average O/C ratio for the total model SOA increases significantly with these new parameters (Fig. SI-24), due to a combination of larger fraction of NT-SOA in the total model SOA, and higher oxygen addition to the secondary NT model species. The total model SOA O/C ratio now overpredicts the measured OOA O/C ratio by $\sim 50 \%$ (for the period between 11:35 a.m.-2 p.m.), suggesting that the oxygen addition per oxidation step of $40 \%$ is too high. Thus it appears that the updated NT SOA model produces significant changes but it is not clearly better at reproducing the observed SOA amount and properties than the original model. Much work remains to better constrain the amounts of material introduced by and the parameters of the NT SOA model.

\subsection{Model sensitivity to the PBL height}

As there is some uncertainty in the evolution of the PBL height for our case study, we calculated the effects of two PBL heights profiles different than the base case shown in 


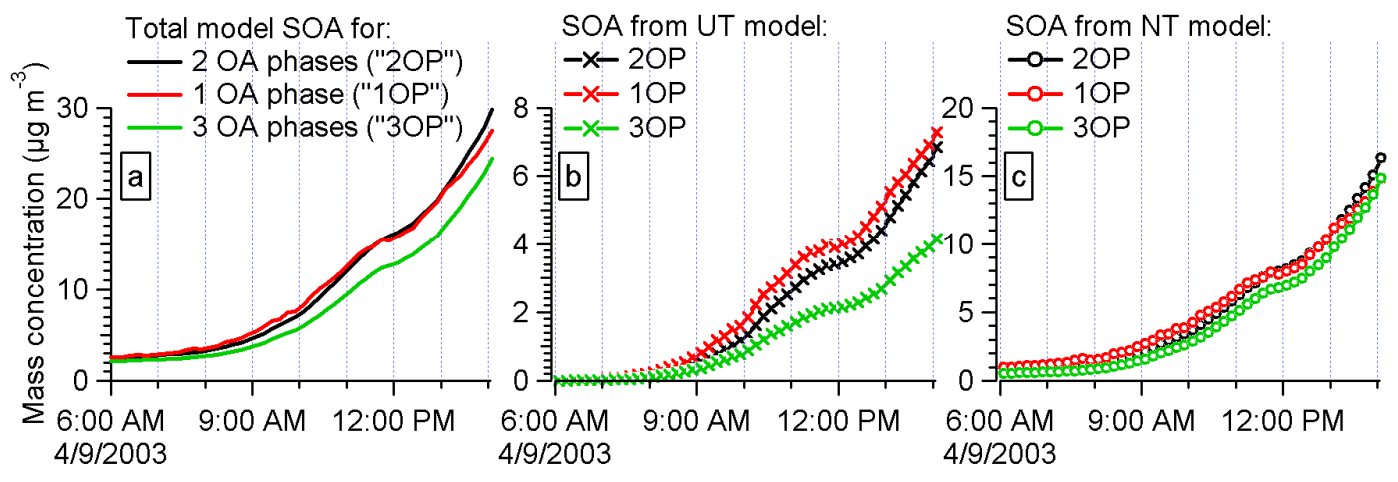

Fig. 15. Results of sensitivity studies of OA partitioning phases/activity coefficients $(\zeta)$. The results are shown for total model SOA (a), UT-SOA (b) and NT-SOA model (c). Each figure shows results for three partitioning cases of model species: "two OA phases" (base case with partitioning as shown in Fig. 3), "one OA phase" (partitioning with $\zeta=1$ as shown in Fig. 14a) and "three OA phases" (as shown in Fig. 14b).
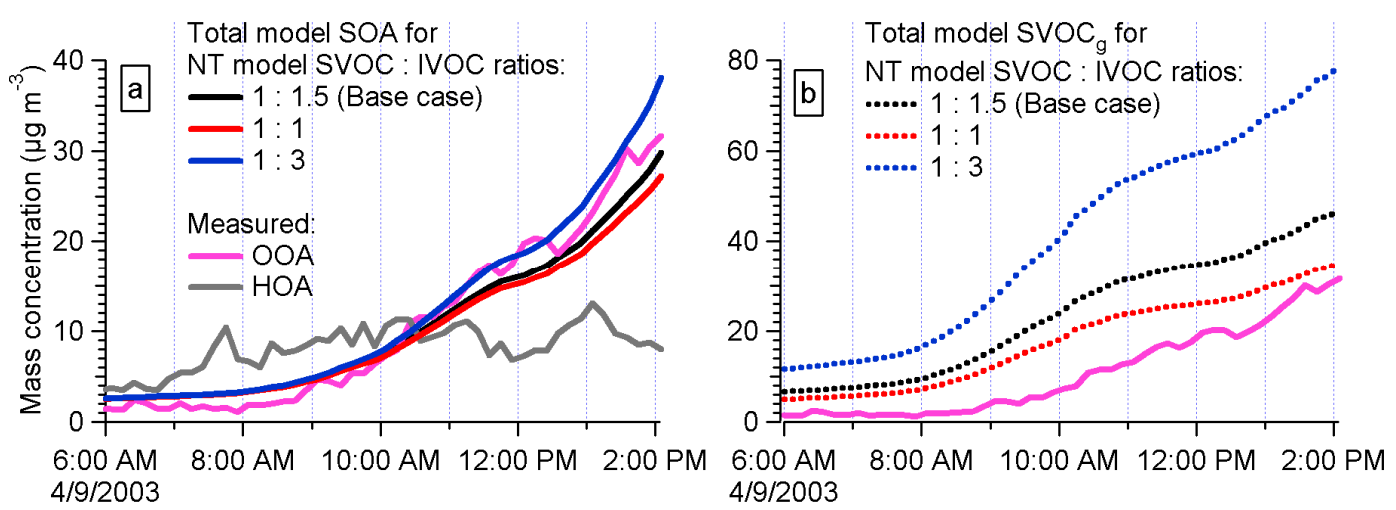

Fig. 16. Results of sensitivity studies of the amount of IVOC mass introduced. The base-case reported by Robinson et al. (2007) has IVOC/SVOC $=1.5$, and we compare it to limiting cases of IVOC/SVOC=1 and 3. Panel (a) shows total NT-SOA and panel (b) shows total model gas-phase SVOC.

Fig. SI-3 on the total model SOA produced. For both simulations the minimum PBL height was kept the same as in the base-case $(750 \mathrm{~m})$, and the maximum PBL height was varied for $\pm 800 \mathrm{~m}$ when compared to the base-case $(1800 \mathrm{~m})$ while the points in between were scaled proportionally. Conceptually, these two PBL sensitivity cases will increase/decrease the dilution of the species in the modeling box, which will change the partitioning of semivolatile species. Decreasing the maximum PBL height to $1000 \mathrm{~m}$ increases the total model SOA and gas-phase SVOC by $16 \%$ and $8 \%$, respectively, when compared to the base-case. Increasing the maximum PBL height to $2600 \mathrm{~m}$ on average decreases the total model SOA and gas-phase SVOC by $9 \%$ and $5 \%$, respectively, when compared to the base-case. It may be surprising at first that these large variations of PBL only result in modest variations in the concentrations of predicted model species. However and unlike in an Eulerian model, in our box model the SOA precursors and oxidants are constrained by observations and the instantaneous formation rates do not change if the dilution changes.
We also used the calculated PBL evolution for 9 April 2003 with the WRF model (A. Hodzic, NCAR, personal communication, 2008) (abbreviated here as "PBLWRF"), and the PBLwRF exhibits somewhat different evolution than the base case PBL used in this study. On 9 April 2003 PBLWRF height at midnight is $\sim 400 \mathrm{~m}$ and is steadily decreasing until 8 a.m. to $\sim 100 \mathrm{~m}$. The growth of PBLWRF starts after 8 a.m., and its height increases until 5 p.m. to $\sim 2500 \mathrm{~m}$. It is clear that $\mathrm{PBL}_{\mathrm{WRF}}$ height changes in a much greater range than the base case PBL, and thus using PBL ${ }_{W R F}$ in model simulations should cause more dilution and lower secondary mass concentrations. Comparison to tracer observations suggest that the collapse of the PBL in WRF at night is too strong compared to reality (Fast et al., 2009; Hodzic et al., 2009) and thus this PBL likely represents an extreme of the possible PBL variation. Indeed, applying $\mathrm{PBL}_{\mathrm{WRF}}$ to our case study results in an average decrease of total model SOA and gas-phase SVOC species mass between 9 a.m. and 2 p.m. of $27 \%$ and $20 \%$, respectively. The comparison of PBL heights for the base case and three variations of PBL height as well as of total model SOA and gas SVOC produced in each case is 
given in Fig. SI-25. In summary, the conclusion of strong underpredicion of the observed SOA with the T and UT models is robust against uncertainties in the PBL evolution, and these uncertainties result in variations of predicted model species in the range $5-27 \%$.

\section{Conclusions}

We have evaluated three new SOA models using a case study from Mexico City: a recently updated parameterization of aromatic SOA from chamber experiments (UT model), the formation of SOA from glyoxal (G model) and the formation of SOA from primary S/IVOC species (NT model). We have also considered the influence of a reduced partitioning of SOA into POA. The updated traditional model by itself fails to produce enough SOA to match the observations by a factor of $\sim 7$, and importantly, even if all semivolatile species in this model would partition to the particle-phase, it would still under predict the observed OOA increase by a factor of $\sim 3$. Glyoxal significantly contributes to SOA formation, and the amount of glyoxal SOA is comparable to that from the updated traditional model. The non-traditional model introduces a large amount of carbon that is not usually considered in models and which is compatible with $\mathrm{OH}$-reactivitiy and integral C-H stretch observations, and has the potential to explain the observed OOA mass in our case study. However, it is critical to observationally constrain the amount and speciation of P-S/IVOC. Thus much experimental work is needed for a realistic assessment of the importance and for constraining the parameters of the NT model.

Characterization of model SOA volatility and atomic O/C ratio and its comparison to measurements provide important tests for SOA models. The volatility of the UT and NT model condensable material (SOA + gas SVOC) was analyzed by simulating equilibrium and kinetic evaporation in a model thermal denuder. The simulated TD evaporation of total and NT model SOA is larger than that measured during MILAGRO-2006. The evaporation of model POA is similar to model results at lower temperatures but too high beyond about $75^{\circ} \mathrm{C}$. Part of these differences could be due to evaporation coefficients smaller than 1 for the ambient OA. Constraining the evaporation coefficients of real aerosols should be a high priority of the future research. The lower volatility of total ambient OA compared to the model could also be due to aging/oligomerization or mixing state effects. The predicted $\mathrm{O} / \mathrm{C}$ ratios are very different for different models, giving on average an $\mathrm{O} / \mathrm{C}$ ratio for total model SOA of $\sim 0.3$, which is somewhat lower than an $\mathrm{O} / \mathrm{C}$ ratio of SOA measured our case study. Dilution has a strong effect on condensable (SOA + gas SVOC) UT and NT model species, and more than $3 / 4$ of UT and NT model SOA evaporates upon dilution by a factor of 10. SOA measured during MILAGRO-2006 does not appear to show such a strong evaporation upon dilution, where SOA (when normalized to $\mathrm{CO}$ ) continues to in- crease as pollution leaves Mexico City. A simple 3-day aging simulation shows that there is a large potential for additional SOA formation in the UT and NT models. Finally, the model is not very sensitive to neither the assumptions of partitioning phases/activities under the conditions of this case study, nor to the potential variations of planetary boundary layer height. An update of the NT model does not clearly improve the comparison with the simulations.

Acknowledgements. This research was supported by NSF (grants ATM-0449815, ATM-0528634, and ATM-0513116), DOE (BER, Atmospheric Science Program, grant DE-FG02-05ER63981), NOAA (grant NA08OAR4310565), and EPA (grant RD-83216101$0) . \mathrm{KDz}$ is grateful for consecutive fellowships from the Advanced Study Program of the National Center for Atmospheric Research, and the Dept. of Chemistry and Biochemistry at the University of Colorado-Boulder. We thank A. Aiken, B. Brune, J. Gaffney, A. Huffman, T. Jobson, K. Johnson, B. Lamb, A. Laskin, N. Marley, C. Wiedinmyer, A. Hodzic, and the CENICA and RAMA staff for providing data, and K. Barsanti, C. Cantrell, N. Donahue, J. Fast, J. Pankow, A. Robinson, C. Song, and R. Zaveri for helpful discussions.

Edited by: L. Molina

\section{References}

Aiken, A. C., DeCarlo, P. F., and Jimenez, J. L.: Elemental Analysis of Organic Species with Electron Ionization High-Resolution Mass Spectrometry, Anal. Chem., 79, 8350-8358, 2007.

Aiken, A. C., DeCarlo, P. F., Kroll, J. H., et al.: O/C and OM/OC Ratios of Primary, Secondary, and Ambient Organic Aerosols with High Resolution Time-of-Flight Aerosol Mass Spectrometry, Environ. Sci. Technol., 42, 4478-4485, 2008.

Aiken, A. C., Salcedo, D., Cubison, M. J., et al.: Mexico City aerosol analysis during MILAGRO using high resolution aerosol mass spectrometry at the urban supersite (T0) - Part 1: Fine particle composition and organic source apportionment, Atmos. Chem. Phys. Discuss., 9, 8377-8427, 2009,

http://www.atmos-chem-phys-discuss.net/9/8377/2009/.

An, W. J., Pathak, R. K., Lee, B. H., and Pandis, S. N.: Aerosol volatility measurement using an improved thermodenuder: Application to secondary organic aerosol, J. Aerosol Sci., 38, 305314, 2007.

Aumont, B., Szopa, S., and Madronich, S.: Modelling the evolution of organic carbon during its gas-phase tropospheric oxidation: development of an explicit model based on a self generating approach, Atmos. Chem. Phys., 5, 2497-2517, 2005, http://www.atmos-chem-phys.net/5/2497/2005/.

Bahreini, R., Keywood, M. D., Ng, N. L., et al.: Measurements of Secondary Organic Aerosol from Oxidation of Cycloalkenes, Terpenes, and m-Xylene Using an Aerodyne Aerosol Mass Spectrometer, Environ. Sci. Technol., 39, 5674-5688, 2005.

Barsanti, K. C. and Pankow, J. F.: Thermodynamics of the formation of atmospheric organic particulate matter by accretion reactions - 2. Dialdehydes, methylglyoxal, and diketones, Atmos. Environ., 39, 6597-6607, 2005. 
Calvert, J. G., Atkinson, R., Kerr, J. A., et al.: The Mechanisms of Atmospheric Oxidation of the Alkenes, Oxford Univ. Press, New York, 2000.

Cammenga, H. K.: Evaporation Mechanisms of Liquids, in: Current Topics in Materials Science 5, edited by: Kaldis, E., NorthHolland, Amsterdam, 335-446, 1980.

Canagaratna, M. R., Jayne, J. T., Jimenez, J. L., et al.: Chemical and Microphysical Characterization of Ambient Aerosols with the Aerodyne Aerosol Mass Spectrometer, Mass Spectr. Rev., 26, 185-222, 2007.

Cappa, C. D., Lovejoy, E. R., and Ravishankara, A. R.: Determination of Evaporation Rates and Vapor Pressures of Very Low Volatility Compounds: A Study of the $\mathrm{C}_{4}-\mathrm{C}_{10}$ and $\mathrm{C}_{12}$ Dicarboxylic Acids, J. Phys. Chem. A, 111, 3099-3109, 2007.

Cappa, C. D., Lovejoy, E. R., and Ravishankara, A. R.: Evaporation Rates and Vapor Pressures of the Even-Numbered C8C18 Monocarboxylic Acids, J. Phys. Chem. A, 112, 3959-3964, 2008.

Carter, W. P. L.: A detailed mechanism for the gas-phase atmospheric reactions of organic compounds, Atmos. Environ., 24, 481-518, 1990.

Chan, A. W. H., Kautzman, K. E., Chhabra, P. S., Surratt, J. D., Chan, M. N., Crounse, J. D., Kürten, A., Wennberg, P. O., Flagan, R. C., and Seinfeld, J. H.: Secondary organic aerosol formation from photooxidation of naphthalene and alkylnaphthalenes: implications for oxidation of intermediate volatility organic compounds (IVOCs), Atmos. Chem. Phys., 9, 3049-3060, 2009, http://www.atmos-chem-phys.net/9/3049/2009/.

Chang, E. I. and Pankow, J. F.: Organic particulate matter formation at varying relative humidity using surrogate secondary and primary organic compounds with activity corrections in the condensed phase obtained using a method based on the Wilson equation, Atmos. Chem. Phys. Discuss., 8, 995-1039, 2008,

http://www.atmos-chem-phys-discuss.net/8/995/2008/.

Chung, S. H. and Seinfeld, J. H.: Global distribution and climate forcing of carbonaceous aerosols, J. Geophys. Res., 107, 4407, doi:10.1029/2001JD001397, 2002.

Cocker, D. R.,, Mader, B. T., Kalberer, M., Flagan, R. C., and Seinfeld, J. H.: The effect of water on gas-particle partitioning of secondary organic aerosol: II. m-xylene and 1,3,5-trimethylbenzene photooxidation systems, Atmos. Environ., 35, 6073-6085, 2001.

Davis, E. J., Ravindran, P., and Ray, A. K.: A review of theory and experiments on diffusion from submicroscopic particles, Chem. Eng. Comm., 5, 251-268, 1980.

DeCarlo, P. F., Dunlea, E. J., Kimmel, J. R., Aiken, A. C., Sueper, D., Crounse, J., Wennberg, P. O., Emmons, L., Shinozuka, Y., Clarke, A., Zhou, J., Tomlinson, J., Collins, D. R., Knapp, D., Weinheimer, A. J., Montzka, D. D., Campos, T., and Jimenez, J. L.: Fast airborne aerosol size and chemistry measurements above Mexico City and Central Mexico during the MILAGRO campaign, Atmos. Chem. Phys., 8, 4027-4048, 2008, http://www.atmos-chem-phys.net/8/4027/2008/.

Docherty, K. S., Stone, E. A., Ulbrich, I. M., et al.: Apportionment of Primary and Secondary Organic Aerosols in Southern California during the 2005 Study of Organic Aerosols in Riverside (SOAR), Environ. Sci. Technol., 42, 7655-7662, 2008.

Donahue, N. M., Robinson, A. L., Stanier, C. O., Pandis, S. N.: Coupled partitioning, dilution, and chemical aging of semivolatile organics, Environ. Sci. Technol., 40, 2635-2643,
2006.

Dzepina, K., Arey, J., Marr, L. C., et al.: Detection of particlephase polycyclic aromatic hydrocarbons in Mexico City using an aerosol mass spectrometer, Int. J. Mass Spec., 263, 152-170, 2007.

de Foy, B., Caetano, E., Magaa, V., Zitcuaro, A., Crdenas, B., Retama, A., Ramos, R., Molina, L. T., and Molina, M. J.: Mexico City basin wind circulation during the MCMA-2003 field campaign, Atmos. Chem. Phys., 5, 2267-2288, 2005, http://www.atmos-chem-phys.net/5/2267/2005/.

de Gouw, J. A., Middlebrook, A. M., Warneke, C., et al.: Budget of organic carbon in a polluted atmosphere: Results from the New England Air Quality Study in 2002, J. Geophys. Res., 110, D16305, doi:10.1029/2004JD005623, 2005.

de Gouw, J. A., Welsh-Bon, D., Warneke, C., Kuster, W. C., Alexander, L., Baker, A. K., Beyersdorf, A. J., Blake, D. R., Canagaratna, M., Celada, A. T., Huey, L. G., Junkermann, W., Onasch, T. B., Salcido, A., Sjostedt, S. J., Sullivan, A. P., Tanner, D. J., Vargas, O., Weber, R. J., Worsnop, D. R., Yu, X. Y., and Zaveri, R.: Emission and chemistry of organic carbon in the gas and aerosol phase at a sub-urban site near Mexico City in March 2006 during the MILAGRO study, Atmos. Chem. Phys., 9, 3425-3442, 2009,

http://www.atmos-chem-phys.net/9/3425/2009/.

de Gouw, J. A. and Jimenez, J. L.: Organic Aerosols in the Earth's Atmosphere, Environ. Sci. Technol., in press, 2009.

Ervens, B., Carlton, A. G., Turpin, B. J., Altieri, K. E., Kreidenweis, S. M., and Feingold, G.: Secondary organic aerosol yields from cloud-processing of isoprene oxidation products, Geophys. Res. Lett., 35, L02816, doi:10.1029/2007GL031828, 2008.

Faulhaber, A. E., Thomas, B. M., Jimenez, J. L., Jayne, J. T., Worsnop, D. R., and Ziemann, P. J.: Characterization of a thermodenuder-particle beam mass spectrometer system for the study of organic aerosol volatility and composition, Atmos. Meas. Tech., 2, 15-31, 2009, http://www.atmos-meas-tech.net/2/15/2009/.

Fast, J. D., Aiken, A. C., Allan, J., Alexander, L., Campos, T., Canagaratna, M. R., Chapman, E., DeCarlo, P. F., de Foy, B., Gaffney, J., de Gouw, J., Doran, J. C., Emmons, L., Hodzic, A., Herndon, S. C., Huey, G., Jayne, J. T., Jimenez, J. L., Kleinman, L., Kuster, W., Marley, N., Russell, L., Ochoa, C., Onasch, T. B., Pekour, M., Song, C., Ulbrich, I. M., Warneke, C., WelshBon, D., Wiedinmyer, C., Worsnop, D. R., Yu, X.-Y., and Zaveri, R.: Evaluating simulated primary anthropogenic and biomass burning organic aerosols during MILAGRO: implications for assessing treatments of secondary organic aerosols, Atmos. Chem. Phys. Discuss., 9, 4805-4871, 2009,

http://www.atmos-chem-phys-discuss.net/9/4805/2009/.

Fierz, M., Vernooij, M. G. C, and Burtscher, H.: An improved lowflow thermodenuder, J. Aerosol Sci., 38, 1163-1168, 2007.

Flores, E., Grutter, M., Galle, B., et al.: EOS Trans. American Geophysical Union, 85(47), Fall Meet. Suppl. Abstract A11A-0003, 2004.

Forstner, H. J. L., Flagan, R. C., and Seinfeld, J. H.: Secondary Organic Aerosol from the Photooxidation of Aromatic Hydrocarbons: Molecular Composition, Environ. Sci. Technol., 31, 13451358, 1997.

Goldstein, A. H. and Gallbally, I. E.: Known and Unexplored Organic Constituents in the Earth's Atmosphere, Environ. Sci. 
Technol., 41, 1514-1521, 2007.

Grieshop, A. P., Donahue, N. M., and Robinson, A. L.: Is the gas-particle partitioning in alpha-pinene secondary organic aerosol reversible?, Geophys. Res. Lett., 34, L14810, doi:10.1029/2007GL029987, 2007.

Grieshop, A. P., Logue, J. M., Donahue, N. M., and Robinson, A. L.: Laboratory investigation of photochemical oxidation of organic aerosol from wood fires 1: measurement and simulation of organic aerosol evolution, Atmos. Chem. Phys., 9, 1263-1277, 2009a, http://www.atmos-chem-phys.net/9/1263/2009/.

Grieshop, A. P., Donahue, N. M., and Robinson, A. L.: Laboratory investigation of photochemical oxidation of organic aerosol from wood fires 2: analysis of aerosol mass spectrometer data, Atmos. Chem. Phys., 9, 2227-2240, 2009b,

http://www.atmos-chem-phys.net/9/2227/2009/.

Grieshop, A. P., Miracolo, M. A., Donahue, N. M., and Robinson, A. L.: Constraining the Volatility Distribution and Gas-Particle Partitioning of Combustion Aerosols Using Isothermal Dilution and Thermodenuder Measurements, Environ. Sci. Technol., 43, 4750-4756, 2009c.

Hallquist, M., Wenger, J. C., Baltensperger, U., Rudich, Y., Simpson, D., Claeys, M., Dommen, J., Donahue, N. M., George, C., Goldstein, A. H., Hamilton, J. F., Herrmann, H., Hoffmann, T., Iinuma, Y., Jang, M., Jenkin, M. E., Jimenez, J. L., Kiendler-Scharr, A., Maenhaut, W., McFiggans, G., Mentel, Th. F., Monod, A., Prévôt, A. S. H., Seinfeld, J. H., Surratt, J. D., Szmigielski, R., and Wildt, J.: The formation, properties and impact of secondary organic aerosol: current and emerging issues, Atmos. Chem. Phys., 9, 5155-5235, 2009,

http://www.atmos-chem-phys.net/9/5155/2009/.

Hand, J. L., Malm, W. C., Laskin, A. J., et al.: Optical, physical and chemical properties of tar balls observed during the Yosemite Aerosol Characterization Study, J. Geophys. Res., 110, D21210, doi:10.1029/2004JD005728, 2005.

Heald, C. L., Jacob, D. J., Park, R. J., et al.: A large organic aerosol source in the free troposphere missing from current models, Geophys. Res. Lett., 32, L18809, doi:10.1029/2005GL023831, 2005.

Heald, C. L., Goldstein, A. H., Allan, J. D., et al.: Total observed organic carbon (TOOC) in the atmosphere: a synthesis of North American observations, Atmos. Chem. Phys., 8, 20072025, 2008, http://www.atmos-chem-phys.net/8/2007/2008/.

Hennigan, C. J., Sullivan, A. P., Fountoukis, C. I., Nenes, A., Hecobian, A., Vargas, O., Peltier, R. E., Case Hanks, A. T., Huey, L. G., Lefer, B. L., Russell, A. G., and Weber, R. J.: On the volatility and production mechanisms of newly formed nitrate and water soluble organic aerosol in Mexico City, Atmos. Chem. Phys., 8, 3761-3768, 2008,

http://www.atmos-chem-phys.net/8/3761/2008/.

Herndon, S. C., Onasch, T. B., Wood, E. C., et al.: The Correlation of Secondary Organic Aerosol with Odd Oxygen in a Megacity Outflow, Geophys. Res. Lett., 35, L15804, doi:10.1029/2008GL034058, 2008.

Hildemann, L. M., Klinedinst, D. B., Klouda, G. A., Currie, L. A., and Cass, G. R.: Sources of Urban Contemporary Carbon Aerosol, Environ. Sci. Technol., 28, 1565-1576, 1994.

Hodzic, A., Jimenez, J. L., Madronich, S., et al.: Modeling organic aerosols during MILAGRO: application of the CHIMERE model and importance of biogenic secondary organic aerosols, Atmos. Chem. Phys. Discuss., 9, 12207-12281, 2009, http://www.atmos-chem-phys-discuss.net/9/12207/2009/.

Huffman, J. A., Ziemann, P. J., Jayne, J. T., Worsnop, D. R., and Jimenez, J. L.: Development and Characterization of a Fast-Stepping Thermodenuder for Chemically-Resolved Aerosol Volatility Measurements, Aerosol Sci. Technol., 42, 395-407, 2008.

Huffman, J. A., Docherty, K. S., Aiken, A. C., Cubison, M. J., Ulbrich, I. M., DeCarlo, P. F., Sueper, D., Jayne, J. T., Worsnop, D. R., Ziemann, P. J., and Jimenez, J. L.: Chemically-resolved aerosol volatility measurements from two megacity field studies, Atmos. Chem. Phys. Discuss., 9, 2645-2697, 2009a, http://www.atmos-chem-phys-discuss.net/9/2645/2009/.

Huffman, J. A., Docherty, K. S., Mohr, C., et al.: ChemicallyResolved Volatility Measurements of Organic Aerosol from Different Sources, Environ. Sci. Technol., 43, 5351-5357, doi:10.1021/es803539d, 2009b.

Jayne, J. T., Leard, D. C., Zhang, X. F., et al.: Development of an aerosol mass spectrometer for size and composition analysis of submicron particles, Aerosol Sci. Technol., 33, 49-70, 2000.

Jimenez, J. L., Jayne, J. T., Shi, Q., et al.: Ambient Aerosol Sampling with an Aerosol Mass Spectrometer, J. Geophys. Res., 108, 8425, doi:10.1029/2001JD001213, 2003.

Johnson, D., Utembe, S. R., Jenkin, M. E., Derwent, R. G., Hayman, G. D., Alfarra, M. R., Coe, H., and McFiggans, G.: Simulating regional scale secondary organic aerosol formation during the TORCH 2003 campaign in the southern UK, Atmos. Chem. Phys., 6, 403-418, 2006, http://www.atmos-chem-phys.net/6/403/2006/.

Johnson, K., Laskin, A., Jimenez, J. L., et al.: Comparative analysis of urban atmospheric aerosol by Particle-Induced X-ray Emission (PIXE), Proton Elastic Scattering Analysis (PESA), and Aerosol Mass Spectrometry (AMS), Environ. Sci. Technol., 42, 6619-6624, 2008.

Kalberer, M., Paulsen, D., Sax, M., et al.: Identification of Polymers as Major Components of Atmospheric Organic Aerosols, Science, 303, 1659-1662, 2004.

Kanakidou, M., Seinfeld, J. H., Pandis, S. N., et al.: Organic aerosol and global climate modelling: a review, Atmos. Chem. Phys., 5, 1053-1123, 2005, http://www.atmos-chem-phys.net/5/1053/2005/.

Kielhorn, J., Pohlenz-Michel, C., Schmidt, S., and Mangelsdorf, I.: Glyoxal, Concise Intl. Chem. Assess. Doc., vol. 57, World Health Organiz., Geneva, Switzerland, 2004.

Kleinman, L. I., Springston, S. R., Daum, P. H., et al.: The time evolution of aerosol composition over the Mexico City plateau, Atmos. Chem. Phys., 8, 1559-1575, 2008, http://www.atmos-chem-phys.net/8/1559/2008/.

Kondo, Y., Miyazaki, Y., Takegawa, N., Miyakawa, T., Weber, R. J., Jimenez, J. L., Zhang, Q., and Worsnop, D. R.: Oxygenated and water-soluble organic aerosols in Tokyo, J. Geophys. Res., 112, D01203, doi:10.1029/2006JD007056, 2007.

Koo, B., Ansari, A. S., and Pandis, S. N.: Integrated Approaches to Modeling the Organic and Inorganic Atmospheric Aerosol Components, Atmos. Environ., 37, 4757-4768, 2003.

Kroll, J. H., Ng, N. L., Murphy, S. M., et al.: Chamber studies of secondary organic aerosol growth by reactive uptake of simple carbonyl compounds, J. Geophys. Res., 110, D23207, doi:10.1029/2005JD006004, 2005a.

Kroll, J. H., Ng, N. L., Murphy, S. M., Flagan, R. C., and Seinfeld, 
J. H.: Secondary organic aerosol formation from isoprene photooxidation under high- $\mathrm{NO}_{\mathrm{x}}$ conditions, Geophys. Res. Lett., 32, L18808, doi:10.1029/2005GL023637, 2005b.

Kroll, J. H. and Seinfeld, J. H.: Chemistry of secondary organic aerosol: Formation and evolution of low-volatility organics in the atmosphere, Atmos. Environ., 42, 3593-3624, 2008.

Lamb, B., Velasco, E., Allwine, E., et al.: Ambient VOC measurements in Mexico City, paper presented at American Meteorological Society Fifth Conference on Urban Environment, Vancouver, B. C., Canada, 23-26 August 2004.

Lanz, V. A., Alfarra, M. R., Baltensperger, U., Buchmann, B., Hueglin, C., and Prévôt, A. S. H.: Source apportionment of submicron organic aerosols at an urban site by factor analytical modelling of aerosol mass spectra, Atmos. Chem. Phys., 7, 15031522, 2007,

http://www.atmos-chem-phys.net/7/1503/2007/.

Lipsky, E. M. and Robinson, A. L.: Effects of Dilution on Fine Particle Mass and Partitioning of Semivolatile Organics in Diesel Exhaust and Wood Smoke, Environ. Sci. Technol., 40, 155-162, 2006.

Liggio, J., Li, S. M., and McLaren, R.: Reactive uptake of glyoxal by particulate matter, J. Geophys. Res., 110, D10304, doi:10.1029/2004JD005113, 2005a.

Liggio, J., Li, S. M., and McLaren, R.: Heterogeneous Reactions of Glyoxal on Particulate Matter: Identification of Acetals and Sulfate Esters, Environ. Sci. Technol., 39, 1532-1541, 2005 b.

Lin, C., Chen, S., Huang, K., Hwang, W., Chien, G. C., and Lin, W.: Characteristics of metals in nano/ultrafine/fine/coarse particles collected beside a heavily trafficked road, Environ. Sci. Technol., 39, 8113-8122, 2005.

Marley, N. A., Gaffney, J. S., Ramos-Villegas, R., and Cárdenas González, B.: Comparison of measurements of peroxyacyl nitrates and primary carbonaceous aerosol concentrations in Mexico City determined in 1997 and 2003, Atmos. Chem. Phys., 7, 2277-2285, 2007,

http://www.atmos-chem-phys.net/7/2277/2007/.

Marr, L. C., Dzepina, K., Jimenez, J. L., Reisen, F., Bethel, H. L., Arey, J., Gaffney, J. S., Marley, N. A., Molina, L. T., and Molina, M. J.: Sources and transformations of particle-bound polycyclic aromatic hydrocarbons in Mexico City, Atmos. Chem. Phys., 6, 1733-1745, 2006, http://www.atmos-chem-phys.net/6/1733/2006/.

Martin-Reviejo, M. and Wirtz, K.: Is Benzene a Precursor for Secondary Organic Aerosol?, Environ. Sci. Technol., 39, 10451054, 2005.

Matsui, H., Koike, M., Takegawa, N., et al.: Secondary Organic Aerosol Formation in Urban Air: Temporal Variations and Possible Contributions from Unidentified Hydrocarbons, J. Geophys. Res., 114, D04201, doi:10.1029/2008JD010164, 2009.

Matsunaga, S. N., Guenther, A. B., Potosnak, M. J., and Apel, E. C.: Emission of sunscreen salicylic esters from desert vegetation and their contribution to aerosol formation, Atmos. Chem. Phys., 8, 7367-7371, 2008, http://www.atmos-chem-phys.net/8/7367/2008/.

Mohr, C., Huffman, J. A., Cubison, M., et al.: Characterization of Primary Organic Aerosol Emissions from Meat Cooking, Trash Burning, and Mobile Sources with High-Resolution Aerosol Mass Spectrometry and Comparison with Ambient and Chamber Observations, Environ. Sci. Technol., 43, 2443-2449,
2009.

Molina, L. T., Kolb, C. E., de Foy, B., Lamb, B. K., Brune, W. H., Jimenez, J. L., Ramos-Villegas, R., Sarmiento, J., ParamoFigueroa, V. H., Cardenas, B., Gutierrez-Avedoy, V., and Molina, M. J.: Air quality in North America's most populous city overview of the MCMA-2003 campaign, Atmos. Chem. Phys., 7, 2447-2473, 2007, http://www.atmos-chem-phys.net/7/2447/2007/.

Murphy, D. M., Cziczo, D. J., Froyd, K. D., et al.: Single-particle mass spectrometry of tropospheric aerosol particles, J. Geophys. Res., 111, D23S32, doi:10.1029/2006JD007340, 2006.

Nemitz, E., Jimenez, J. L., Huffman, J. A., et al.: An eddycovariance system for the measurement of surface/atmosphere exchange fluxes of submicron aerosol chemical species - first application above an urban area, Aerosol Sci. Technol., 42, 636657, 2008.

Ng, N. L., Kroll, J. H., Chan, A. W. H., Chhabra, P. S., Flagan, R. C., and Seinfeld, J. H.: Secondary organic aerosol formation from m-xylene, toluene, and benzene, Atmos. Chem. Phys., 7, 3909-3922, 2007, http://www.atmos-chem-phys.net/7/3909/2007/.

Odum, J. R., Hoffmann, T., Bowman, F., et al.: Gas/Particle Partitioning and Secondary Organic Aerosol Yields, Environ. Sci. Technol., 30, 2580-2585, 1996.

Odum, J. R., Jungkamp, T. P. W., Griffin, R. J., et al.: Aromatics, Reformulated Gasoline, and Atmospheric Organic Aerosol Formation, Environ. Sci. Technol., 31, 1890-1897, 1997.

Offenberg, J. H., Kleindienst, T. E., Jaoui, M., et al.: Thermal properties of secondary organic aerosols, Geophys. Res. Lett., 33, L03816, doi:10.1029/2005GL024623, 2006.

Paatero, P.: Least squares formulation of robust non-negative factor analysis, Chemometrics and Intelligent Laboratory Systems, 37, 23-35, 1997.

Paatero, P. and Tapper, U.: Positive Matrix Factorization: a nonnegative factor model with optimal utilization of error estimates of data values, Environmetrics, 5, 111-126, 1994.

Pandis, S. N., Harley, R. A., Cass, G. R., and Seinfeld, J. H.: Secondary organic aerosol formation and transport, Atmos. Environ., 26, 2269-2282, 1992.

Pankow, J. F.: An absorption model of gas/particle partitioning of organic compounds in the atmosphere, Atmos. Environ., 28, 185-188, 1994a.

Pankow, J. F.: An absorption model of the gas/aerosol partitioning involved in the formation of secondary organic aerosol, Atmos. Environ., 28, 189-193, 1994b.

Pound, G. M.: Selected values of evaporation and condensation coefficients for simple substances, J. Phys. Chem. Ref. Data, 1, 135-146, 1972.

Presto, A. A., Miracolo, M. A., Kroll, J. H., Worsnop, D. R., Robinson, A. L., and Donahue, N. M.: Intermediate-Volatility Organic Compounds: A Potential Source of Ambient Oxidized Organic Aerosol, Environ. Sci. Technol., 43, 4744-4749, 2009.

Robinson, A. L., Donahue, N. M., Shrivastava, M. K., et al.: Rethinking Organic Aerosols: Semivolatile Emissions and Photochemical Aging, Science, 315, 1259-1262, 2007.

Sage, A. M., Weitkamp, E. A., Robinson, A. L., and Donahue, N. M.: Evolving mass spectra of the oxidized component of organic aerosol: results from aerosol mass spectrometer analyses of aged diesel emissions, Atmos. Chem. Phys., 8, 1139-1152, 2008, 
http://www.atmos-chem-phys.net/8/1139/2008/.

Salcedo, D., Dzepina, K., Onasch, T. B., et al.: Characterization of ambient aerosols in Mexico City during the MCMA-2003 campaign with Aerosol Mass Spectrometry - Part I: quantification, shape-related collection efficiency, and comparison with collocated instruments, Atmos. Chem. Phys. Discuss., 5, 4143-4182, 2005 , http://www.atmos-chem-phys-discuss.net/5/4143/2005/.

Salcedo, D., Onasch, T. B., Dzepina, K., Canagaratna, M. R., Zhang, Q., Huffman, J. A., DeCarlo, P. F., Jayne, J. T., Mortimer, P., Worsnop, D. R., Kolb, C. E., Johnson, K. S., Zuberi, B., Marr, L. C., Volkamer, R., Molina, L. T., Molina, M. J., Cardenas, B., Bernab, R. M., Mrquez, C., Gaffney, J. S., Marley, N. A., Laskin, A., Shutthanandan, V., Xie, Y., Brune, W., Lesher, R., Shirley, T., and Jimenez, J. L.: Characterization of ambient aerosols in Mexico City during the MCMA-2003 campaign with Aerosol Mass Spectrometry: results from the CENICA Supersite, Atmos. Chem. Phys., 6, 925-946, 2006,

http://www.atmos-chem-phys.net/6/925/2006/.

Salcedo, D., Onasch, T. B., Canagaratna, M. R., Dzepina, K., Huffman, J. A., Jayne, J. T., Worsnop, D. R., Kolb, C. E., Weimer, S., Drewnick, F., Allan, J. D., Delia, A. E., and Jimenez, J. L.: Technical Note: Use of a beam width probe in an Aerosol Mass Spectrometer to monitor particle collection efficiency in the field, Atmos. Chem. Phys., 7, 549-556, 2007,

http://www.atmos-chem-phys.net/7/549/2007/.

San Martini, F. M., Dunlea, E. J., Volkamer, R., Onasch, T. B., Jayne, J. T., Canagaratna, M. R., Worsnop, D. R., Kolb, C. E., Shorter, J. H., Herndon, S. C., Zahniser, M. S., Salcedo, D., Dzepina, K., Jimenez, J. L., Ortega, J. M., Johnson, K. S., McRae, G. J., Molina, L. T., and Molina, M. J.: Implementation of a Markov Chain Monte Carlo method to inorganic aerosol modeling of observations from the MCMA-2003 campaign Part II: Model application to the CENICA, Pedregal and Santa Ana sites, Atmos. Chem. Phys., 6, 4889-4904, 2006, http://www.atmos-chem-phys.net/6/4889/2006/.

Seinfeld, J. H. and Pandis, S. N.: Atmospheric Chemistry and Physics: From Air Pollution to Climate Change, WileyInterscience, New York, 1998.

Sheehy, P. M., Volkamer, R., Molina, L. T., and Molina, M. J.: Oxidative capacity of the Mexico City atmosphere - Part 2: A $\mathrm{RO}_{\mathrm{x}}$ radical cycling perspective, Atmos. Chem. Phys. Discuss., 8, 5359-5412, 2008,

http://www.atmos-chem-phys-discuss.net/8/5359/2008/.

Shilling, J. E., Chen, Q., King, S. M., Rosenoern, T., Kroll, J. H., Worsnop, D. R., DeCarlo, P. F., Aiken, A. C., Sueper, D., Jimenez, J. L., and Martin, S. T.: Loading-dependent elemental composition of -pinene SOA particles, Atmos. Chem. Phys., 9, 771-782, 2009,

http://www.atmos-chem-phys.net/9/771/2009/.

Shirley, T. R., Brune, W. H., Ren, X., Mao, J., Lesher, R., Cardenas, B., Volkamer, R., Molina, L. T., Molina, M. J., Lamb, B., Velasco, E., Jobson, T., and Alexander, M.: Atmospheric oxidation in the Mexico City Metropolitan Area (MCMA) during April 2003, Atmos. Chem. Phys., 6, 2753-2765, 2006, http://www.atmos-chem-phys.net/6/2753/2006/.

Shrivastava, M. K., Lipsky, E. M., Stanier, C. O., and Robinson, A. L.: Modeling Semivolatile Organic Aerosol Mass Emissions from Combustion Systems, Environ. Sci. Technol., 40, 2671-
2677, 2006.

Shrivastava, M. K., Lane, T. E., Donahue, N. M., Pandis, S. N., and Robinson, A. L.: Effects of gas particle partitioning and aging of primary emissions on urban and regional organic aerosol concentrations, J. Geophys. Res., 113, D18301, doi:10.1029/2007JD009735, 2008.

Song, C., Zaveri, R. A., Alexander, M. L., et al.: Effect of hydrophobic primary organic aerosols on secondary organic aerosol formation from ozonolysis of a-pinene, Geophys. Res. Lett., 34, L20803, doi:10.1029/2007GL030720, 2007.

Stanier, C. O., Pathak, R. K., and Pandis, S. N.: Measurements of volatility of aerosols from alpha-pinene ozonolysis. Environ. Sci. Technol., 41, 2756-2763, 2007.

Takegawa, N., Miyakawa, T., Kondo, Y., et al.: Seasonal and diurnal variations of submicron organic aerosol in Tokyo observed using the Aerodyne aerosol mass spectrometer, J. Geophys. Res., 111, D11206, doi:10.1029/2005JD006515, 2006.

Tsimpidi, A. P., Karydis, V. A., Zavala, M., Lei, W., Molina, L., Ulbrich, I. M., Jimenez, J. L., and Pandis, S. N.: Evaluation of the volatility basis-set approach for the simulation of organic aerosol formation in the Mexico City metropolitan area, Atmos. Chem. Phys. Discuss., 9, 13693-13737, 2009, http://www.atmos-chem-phys-discuss.net/9/13693/2009/.

Tobias, H. J. and Ziemann, P. J.: Compound Identification in Organic Aerosols Using Temperature-Programmed Thermal Desorption Particle Beam Mass Spectrometry, Anal. Chem., 71, 3428-3435, 1999.

Tobias, H. J. and Ziemann, P. J.: Thermal Desorption Mass Spectrometric Analysis of Organic Aerosol Formed from Reactions of 1-Tetradecene and $\mathrm{O}_{3}$ in the Presence of Alcohols and Carboxylic Acids, Environ. Sci. Technol., 34, 2105-2115, 2000.

Ulbrich, I. M., Canagaratna, M. R., Zhang, Q., Worsnop, D. R., and Jimenez, J. L.: Interpretation of organic components from Positive Matrix Factorization of aerosol mass spectrometric data, Atmos. Chem. Phys., 9, 2891-2918, 2009, http://www.atmos-chem-phys.net/9/2891/2009/.

Velasco, E., Lamb, B., Westberg, H., Allwine, E., Sosa, G., ArriagaColina, J. L., Jobson, B. T., Alexander, M. L., Prazeller, P., Knighton, W. B., Rogers, T. M., Grutter, M., Herndon, S. C., Kolb, C. E., Zavala, M., de Foy, B., Volkamer, R., Molina, L. T., and Molina, M. J.: Distribution, magnitudes, reactivities, ratios and diurnal patterns of volatile organic compounds in the Valley of Mexico during the MCMA 2002 \& 2003 field campaigns, Atmos. Chem. Phys., 7, 329-353, 2007, http://www.atmos-chem-phys.net/7/329/2007/.

Volkamer, R., Etzkorn, T., Geyer, A., and Platt, U.: Correction of the oxygen interference with UV spectroscopic (DOAS) measurements of monocyclic aromatic hydrocarbons in the atmosphere, Atmos. Environ., 32, 3731-3747, 1998.

Volkamer, R., Platt, U., and Wirtz, K.: Primary and secondary glyoxal formation from aromatics: Experimental evidence for the bicycloalkyl-radical pathway from benzene, toluene, and pxylene, J. Phys. Chem. A, 105, 7865-7874, 2001.

Volkamer, R., Molina, L. T., Molina, M. J., Shirley, T., and Brune, W. H.: DOAS measurement of glyoxal as an indicator for fast VOC chemistry in urban air, Geophys. Res. Lett., 32, L08806, doi:10.1029/2005GL022616, 2005.

Volkamer, R., Jimenez, J. L., San Martini, F., et al.: Secondary organic aerosol formation from anthropogenic air pollution: Rapid 
and higher than expected, Geophys. Res. Lett., 33, L17811, doi:10.1029/2006GL026899, 2006.

Volkamer, R., San Martini, F., Molina, L. T., et al.: A missing sink for gas-phase glyoxal in Mexico City: Formation of secondary organic aerosol, Geophys. Res. Lett., 34, L19807, doi:10.1029/2007GL030752, 2007a.

Volkamer, R., Sheehy, P. M., Molina, L. T., and Molina, M. J.: Oxidative capacity of the Mexico City atmosphere - Part 1: A radical source perspective, Atmos. Chem. Phys. Discuss., 7, 53655412, 2007b,

http://www.atmos-chem-phys-discuss.net/7/5365/2007/.

Volkamer, R., Ziemann, P. J., and Molina, M. J.: Secondary Organic Aerosol Formation from Acetylene $\left(\mathrm{C}_{2} \mathrm{H}_{2}\right)$ : seed effect on SOA yields due to organic photochemistry in the aerosol aqueous phase, Atmos. Chem. Phys., 9, 1907-1928, 2009, http://www.atmos-chem-phys.net/9/1907/2009/.

Weber, R. J., Sullivan, A. P., Peltier, R. E., et al.: A study of secondary organic aerosol formation in the anthropogenicinfluenced southeastern United States, J. Geophys. Res., 112, D13302, doi:10.1029/2007JD008408, 2007.

Wesely, M. L.: Parameterization of surface resistances to gaseous dry deposition in regional-scale numerical models, Atmos. Environ., 23, 1293-1304, 1989.
Yamasaki, H., Kuwata, K., and Miyamoto, H.: Effects of temperature on aspects of airborne polycyclic aromatic hydrocarbons, Environ. Sci. Technol., 16, 189-194, 1982.

Yu, J., Jeffries, H. E., and Lelacheur, R. M.: Identifying Airborne Carbonyl Compounds in Isoprene Atmospheric Photooxidation Products by Their PFBHA Oximes Using Gas Chromatography/Ion Trap Mass Spectrometry, Environ. Sci. Technol., 29, 1923-1932, 1995.

Zaveri, R. A., Chapman, E. G., Easter, R. C., et al.: Modeling GasAerosol Processes during MILAGRO 2006, Eos Trans. AGU, 88(52), Fall Meet. Suppl., Abstract A33D-1570, 2007.

Zhang, Q., Alfarra, M. R. Worsnop, D. R., et al.: Deconvolution and Quantification of Hydrocarbon-like and Oxygenated Organic Aerosols Based on Aerosol Mass Spectrometry, Environ. Sci. Technol., 39, 4938-4952, 2005a.

Zhang, Q., Worsnop, D. R., Canagaratna, M. R., and Jimenez, J. L.: Hydrocarbon-like and oxygenated organic aerosols in Pittsburgh: insights into sources and processes of organic aerosols, Atmos. Chem. Phys., 5, 3289-3311, 2005b, http://www.atmos-chem-phys.net/5/3289/2005/.

Zhang, Q., Jimenez, J. L., Canagaratna, M. R., et al.: Ubiquity and dominance of oxygenated species in organic aerosols in anthropogenically-influenced Northern Hemisphere midlatitudes, Geophys. Res. Lett., 34, L13801, doi:13810.11029/12007GL029979, 2007. 